\title{
Study on the Tribological Behavior of Wear and Friction Coefficient on AISI M35 High-Speed Steel with and without DLC Coating
}

\author{
Paulo Sérgio Martins ${ }^{a}$ (D), José Rubens Gonçalves Carneiro ${ }^{a}$ (D), Elhadji Cheikh Talibouya Ba ${ }^{b *}$ (D), \\ Vitor Ferreira Vieira ${ }^{c}$ (D), Diego Boaventura Amaral ${ }^{d}$, Nilson Cristino da Cruz ${ }^{e}$
}

\author{
aPontifícia Universidade Católica de Minas Gerais, Departamento de Engenharia Mecânica, \\ Rua Dom José Gaspar 500, Bairro Coração Eucarístico, CEP: 30535-901, Belo Horizonte, MG, Brasil. \\ ${ }^{b}$ Centro Federal de Educação Tecnológica de Minas Gerias, Programa de Pós-graduação em \\ Engenharia de Materiais, Av. Amazonas 5253, Nova Suiça, CEP 30421-169, \\ Belo Horizonte, MG, Brasil. \\ ${ }^{c}$ Centro Federal de Educação Tecnológica de Minas Gerais, Programa de Pós-graduação em \\ Engenharia de Mecânica, Av. Amazonas 7675, Nova Gameleira, CEP: 30510-000, \\ Belo Horizonte, MG, Brasil. \\ ${ }^{d}$ Fiat Chrysler Automobiles, Departamento de Engenharia de Manufatura, \\ Av. do Contorno da Fiat, 3455, CEP 32530-490, Betim, MG, Brasil. \\ eUniversidade Estadual Paulista Júlio de Mesquita Filho, Departamento de Automação e Engenharia \\ de Controle, Av. 3 de Março, 511, CEP 18087-180, Sorocaba, SP, Brasil.
}

Received: December 17, 2020; Revised: September 6, 2021; Accepted: October 8, 2021

\begin{abstract}
To improve the wear resistance of cutting tools made of high-speed steel, the Diamond-Like Carbon (DLC) coating appears as a promising alternative. There are several methods to assess wear, however, it is a challenge for manufacturing engineering to work with thin films, due to the uncertainty in the boundary of the substrate and the coating. Based on this concern, this study proposed the evaluation of the tribological behavior of the DLC coating deposited on AISI M35 steel, seeking to predict its behavior in machining conditions based on characterizations, nano-indentation, micro-abrasion and ball-on-disc test. Results showed that the DLC coating produced for this study consists mainly of $\mathrm{sp}^{2}$ hybridizations. The results of the nano-indentation showed that DLC coating may have a better wear resistance when compared to high-speed steel, and the nano-hardness and Young's modulus do not necessarily obey a positive correlation. Compared to high-speed steel, DLC provided reductions of $71 \%$ and $69 \%$ without micro-abrasive wear and without friction coefficient during sliding, respectively.
\end{abstract}

Keywords: High-Speed Steel, AISI M35, Thin films, DLC, Abrasive wear, Friction coefficient, Tribological surface.

\section{Introduction}

Diamond-Like Carbon (DLC) refers to allotropic forms of carbon that are metastable ${ }^{1}$ and have an amorphous structure consisting of carbon-carbon bonds in $\mathrm{sp}^{2}$ configuration (graphite) and carbon-carbon bonds in $\mathrm{sp}^{3}$ configuration (diamond) ${ }^{2}$. Hydrogen can also be incorporated into the chemical composition along with the $\mathrm{sp}^{3}$ configuration, which will classify the DLC as hydrogenated or non-hydrogenated according to a percentage content. Through the ternary carbon phase diagram, it is possible to identify, in general, four classes of DLC: (1) a-C, predominant in $\mathrm{sp}^{2}$ bonds; (2) a-C: $\mathrm{H}$, hydrogenated and predominant in $\mathrm{sp}^{2}$ bonds; (3) ta-C, predominant in $\mathrm{sp}^{3}$ bonds; and (4) ta-C: $\mathrm{H}$, hydrogenated and predominant in $\mathrm{sp}^{3}$ bonds ${ }^{3}$.

DLC has received notable prominence when applied as a coating for several components used, for example, mechanical components of internal combustion engines,

*e-mail: cheikh.ba460@hotmail.com anti-reflective surfaces for solar cells or optical elements, protective coatings on biomedical implants, prostheses and magnetic disks ${ }^{4-7}$. This diversity of application is due, in general, to the properties of wear resistance, low friction coefficient, corrosion resistance and chemical inertness ${ }^{8}$, in addition to its manufacturing process being considered less aggressive to the environment ${ }^{2}$. A greater emphasis has been placed on all the strategic optimization applications that can assist the advancement of industries in the face of the current challenges of combining quality, quantity, time, cost and environmental impacts ${ }^{9,10}$.

The same is true for machining processes, where DLC is used as a coating for cutting tools (especially high-speed steel and tungsten carbide ${ }^{11}$, with the aim of improving wear resistance $\mathrm{f}^{6,12,13}$. Cut-off parameters and tools need to be selected to combine tool life with the quality of the machined product ${ }^{6,13}$. Tool wear occurs due to plastic deformation, adhesion, and the formation of BUE (Built-Up 
Edge). The greater chemical affinity with the material of the machined part also contributes to tool wear ${ }^{10}$.

The development of materials engineering made it possible to replace steel and cast iron with aluminum alloys in several applications due to the introduction of reinforcement particles that are able to modify the microstructure and provide an increase in mechanical strength ${ }^{14}$. However, studies have shown that the machinability of these materials has multiple negative aspects, such as adhesion and abrasion ${ }^{6}$. When drilling aluminum alloys, for example, the flow of the formed chip is hard due to the adhesion that occurs on the tool's exit surface, which leads to tool failure ${ }^{12}$. Regardless of the application of cutting fluids, studies show that DLC provides improvements in the machining of aluminum alloys ${ }^{6,13}$.

Amorphous carbon coatings of grades a-C, a-C: $\mathrm{H}$ and ta-C: $\mathrm{H}$ are often produced by physical vapor deposition (PVD) and chemical vapor deposition (CVD) processes ${ }^{15}$. The high temperatures of the CVD, above $800^{\circ} \mathrm{C}$, can compromise the final product due to the high thermal loads transmitted to the substrate and the thermal stresses formed at the interface. The formation of a fragile layer, called "eta phase", at the interface can considerably reduce the mechanical properties of the substrate and the adhesion of the film. Thus, some cutting tool applications are not recommended to use this deposition process: cutting tools that require greater toughness, impact resistance and plastic deformation for broaching, drilling and milling processes, among others. In these cases, the PVD process can be a solution, as it involves deposition temperatures that do not cause significant microstructural changes ${ }^{16,17}$. Attention must also be paid to the compatibility between the substrate and coating, the properties of the DLC will only be valid if there is good adhesion. The "adhesion" theme is frequently discussed regarding the application of DLC, since its behavior in elastic phase differs from the behavior of the substrate. This difference in behavior can be explained by the difference in the material Young's modulus ${ }^{1,13}$. To reduce the intrinsic disadvantages of amorphous carbon films, studies are carried out to investigate the addition of elements (doping and/ or interface layer) such as titanium, chromium, tungsten, nitrogen, silicon, among others ${ }^{2,18}$ evaluated the applicability of DLC a-C: $\mathrm{H}$ as a coating for cutting tools in the dry turning process of hardened AISI 52100 steel. It was found that DLC is very resistant to the adhesion mechanism. However, there was a sharp detachment of the film in the direction of chip exit, which was attributed to the quality of adhesion of the film that was insufficient to support the increase in the feed. In addition, the authors stated that the microstructure of the DLC remains stable up to $260^{\circ} \mathrm{C}$, above this temperature its conversion to graphite begins ${ }^{19}$. cited some considerations on the use of hydrogenated (approximately $40 \%$ hydrogen) and non-hydrogenated (up to $2 \%$ hydrogen) DLC related to the sensitivity of mechanical properties due to changes in humidity and temperature in the environment. According to the authors, the friction coefficient can increase, suddenly, above $200^{\circ} \mathrm{C}$ and $100^{\circ} \mathrm{C}$ respectively for the mentioned DLC classes.

12 investigated the machining of a SAE 323 aluminum alloy using carbide drills, evaluating the quality of the process according to the deviations in roundness, cylindricity, diameter and the roughness of the hole walls. Before depositing the DLC, a layer of silicon was applied over the carbide substrate to improve the adhesion property of the DLC, which, according to the authors, is compromised when DLC is applied directly to the substrate. Results showed a reduction in the roughness of the holes machined with the coated drill compared to the uncoated drill, being justified by the hardness and chemical inertia properties of the DLC. In addition, better results from deviations in circularity, cylindricity and diameter were also obtained with the coated drill.

${ }^{6}$ investigated the use of DLC as a coating for AISI M35 high-speed steel tools for machining holes in combustion engine cylinder heads made of an aluminum alloy containing approximately $8 \%$ silicon. Between three thousand and five thousand holes were machined under different conditions due to the cutting speed and tool condition (with and without DLC). The holes were evaluated regarding dimensional accuracy (circularity and cylindricity) and integrity (roughness). From the results, it was observed that DLC coating did not provide significant improvements in the hole quality. According to the authors, after machining 500 parts, the quality parameters of the holes showed sudden changes, which were attributed to the failure of the DLC adhesion. According to the authors, the large-scale application of DLC on high-speed steel tools need to be further studied.

A similar study aimed to machine ten thousand holes in an aluminum-silicon alloy ${ }^{13}$. Carbide drills with and without DLC coating were used and compared by means of statistical analysis in different cutting speed conditions, with the diameter deviation of the machined holes as the variable response. Raman spectroscopy, X-ray photoelectron spectroscopy and nano-indentation techniques were used to characterize the coating as an a-C class DLC with a $\mathrm{sp}^{3} / \mathrm{sp}^{2}$ ratio of approximately $24 \%$ with mechanical properties of $18 \mathrm{GPa}$ and $234 \mathrm{GPa}$, hardness and Young's modulus, respectively. Statistical results showed significant improvements in response variables in holes machined at low cutting speed by the coated tool compared to the uncoated tool. The improvements in the machining process were attributed to the reduction of the friction coefficient in the tribosystem formed between the tool's exit surface and the chip flow.

In machining processes, the high temperature gradient, compression, shear stresses and the deformation rate are factors that constitute the complex operating condition of the cutting tools. The combination of these factors can make it difficult to understand or overlap the real contributions presented by the coatings in machining tests. The selection of coatings through a separate evaluation of properties such as hardness, toughness, composition and morphology, for example, can provide unsatisfactory results for practical applications ${ }^{11}$. In such cases, robust techniques for assessing the performance of coatings can be used to assist scientific studies. These techniques are based on the study of tribology: the friction coefficient, wear and lubrication mechanisms.

Friction and wear are considered as properties dependent on each formed tribosystem, which involves environmental conditions (humidity, lubrication and temperature), hardness ratio of the materials, roughness of the surfaces in contact, metallurgical compatibility of the materials, formation of debris and oxides, contact pressure, among others ${ }^{11,15,20}$. 
Several tribological tests are available according to the expected characterization objectives, which generally require low cost of experimental apparatus and the possibility of using small-scale samples ${ }^{21}$. The micro-abrasion wear test is one example, in which it is possible to measure the thickness and abrasive wear resistance of bulk materials as well as coatings ${ }^{22}$. Another test used is the sliding wear test, performed on tribometers in configurations, in general, pinon-disc and ball-on-disc. In this test, it is possible to monitor the behavior of the friction coefficient between two surfaces in contact and relative movement. Variables such as normal load, peripheral speed, ambient and lubrication conditions are often controlled.

Different non-hydrogenated DLC films were deposited on steel and silicon samples to investigate the influence of nitrogen doping on the friction coefficient under lubrication in the pin-on-disc wear test ${ }^{23}$. The authors observed that DLC doping with different nitrogen levels did not provide a significant reduction in the friction coefficient.

The influence of the deposition parameters of the HiPIMS process (High Power Impulse Magnetron Sputtering) on the chemical composition, structure, mechanical and tribological properties of the DLC was studied ${ }^{8}$. Different films were deposited on samples (discs) of SKH51 steel (HRC 65), which were tested on a ball-on-disc tribometer. According to the authors, all coatings showed good tribological performances, characterized by low wear rate.

After performing wear tests by reciprocal sliding in the ball-on-disc configuration with a-C: H DLC films ${ }^{15}$, observed through Raman spectroscopy the increase of the $\mathrm{I}_{\mathrm{D}} / \mathrm{I}_{\mathrm{G}}$ ratio in the wear track compared to the region of the surface not affected by the formation of the tribosystem. The authors concluded that the main wear mechanism of the analyzed DLC is graphitization. At the same time, the formation of graphite at the contact interfaces (tool-chip and tool-workpiece) contributes to the reduction of machining forces, adhesion and abrasion ${ }^{18}$.

Based on the overview presented, this study proposed to evaluate the tribological behavior of the DLC film deposited on AISI M35 high-speed steel, seeking to predict its behavior under machining conditions based on structural characterizations, nano-indentation and performance in micro-abrasion wear tests and by pin-on-disc wear test. The structure of the study is presented in three main topics: "Experimental procedures", "Results and Discussion" and "Conclusion". The first topic presents the information on AISI M35 steel, the coating deposition process, the techniques used for chemical, structural, roughness, nano-hardness characterization, Young's modulus, in addition to the apparatus used for the tribological wear tests by micro-abrasion and pin-on-disc wear test. In the next topic, the results are presented and discussed separately in the following subtopics: "Materials characterization" addressing the microstructural analysis of AISI M35 steel, the deposition and classification of the DLC, analysis of roughness changes after deposition of the coating and the comparison of mechanical properties nano-hardness and Young's modulus between steel and DLC. "Tribological experiments" presenting the results obtained in the micro-abrasion and pin-on-disc wear test. Finally, the main results and analyzes are summarized in a conclusion.

\section{Experimental Procedures}

For the development of this study, the following experimental procedure was elaborated. According to Figure 1, AISI M35 steel specimens were prepared in blocks measuring 20x20x5 mm, whose final surface finish was obtained by grinding process. Then, the total amount of the specimens was divided by half, one part for the DLC coating study and the other for HSS itself. The study of material characterization was composed by the analysis of surface roughness, hardness, Young's modulus, chemical composition, coating thickness and its content of $\mathrm{sp}^{3}$ and $\mathrm{sp}^{2}$ hybridizations. The study of materials tribological behavior was composed by the tribological tests of microabrasive wear (calowear) and sliding wear (ball-on-disc), evaluating the friction and wear coefficients, in addition to the generated surface wear.

The characterization of AISI M35 HSS, also known as HS 6-5-2-5, started with quantitative chemical analysis using optical emission spectroscopy, Spectro Maxx equipment - EIME: 012283055. An arithmetic average value of the chemical elements between three measurements was considered for this study. Table 1 shows the measured chemical composition. The result of this analysis was compared with the chemical composition found by other authors who studied the same material ${ }^{24-26}$, in addition to the ASTM A600 - Standard Specification for High Speed Steel Tools (Figure 2). The microstructure of the HSS was analyzed using scanning electron microscopy (SEM) on the TESCAN VEGA 3 equipment, equipped with array of tungsten filament, $300 \mathrm{~nm}$ resolution at $30 \mathrm{kV}$ and $8 \mathrm{~nm}$ resolution at $3 \mathrm{kV}$, with secondary electrons (SE) and scattered electrons (BSE), magnification of $2 \mathrm{X}-1,000.00 \mathrm{X}$ and electron beam energy from $2 \mathrm{eV}$ to $30 \mathrm{kV}$. Atomic force microscopy (AFM), AFM MPFP3D SA Asylum Research equipment, was used to measure surface roughness, hardness and the elasticity modulus (coupled diamond nano-indenter, Berkovich type).

High-Speed Steel has a high percentage of alloying elements such as tungsten (W), molybdenum (Mo), chromium $(\mathrm{Cr})$, cobalt $(\mathrm{Co})$, vanadium $(\mathrm{V})$ and niobium $(\mathrm{Nb})$. Its main characteristic is high hot hardness and toughness, making possible to be used at temperatures up to $600^{\circ} \mathrm{C}^{27}$. The chemical composition of HSS showed an average of $0.86 \%$ carbon, an element that can vary between $0.70 \%$ and $1.60 \%$. Carbon is the primordial alloy element, responsible for the formation of the martensitic matrix and the primary steel carbides and, as a consequence, the increase

Table 1. AISI M35 chemical composition

\begin{tabular}{ccccccccccc}
\hline Element & $\mathrm{C}$ & $\mathrm{Mn}$ & $\mathrm{P}$ & $\mathrm{S}$ & $\mathrm{Si}$ & $\mathrm{Cr}$ & $\mathrm{V}$ & $\mathrm{W}$ & $\mathrm{Mo}$ & $\mathrm{Co}$ \\
\hline Average composition (wt.\%) & 0.86 & 0.25 & 0.02 & $<0.001$ & 0.23 & 4.42 & 1.39 & 5.36 & 3.82 & 0.54 \\
\hline Standard deviation (wt.\%) & 0.01 & 0.00 & 0.00 & 0.00 & 0.00 & 0.01 & 0.01 & 0.04 & 0.04 & 0.00 \\
\hline
\end{tabular}




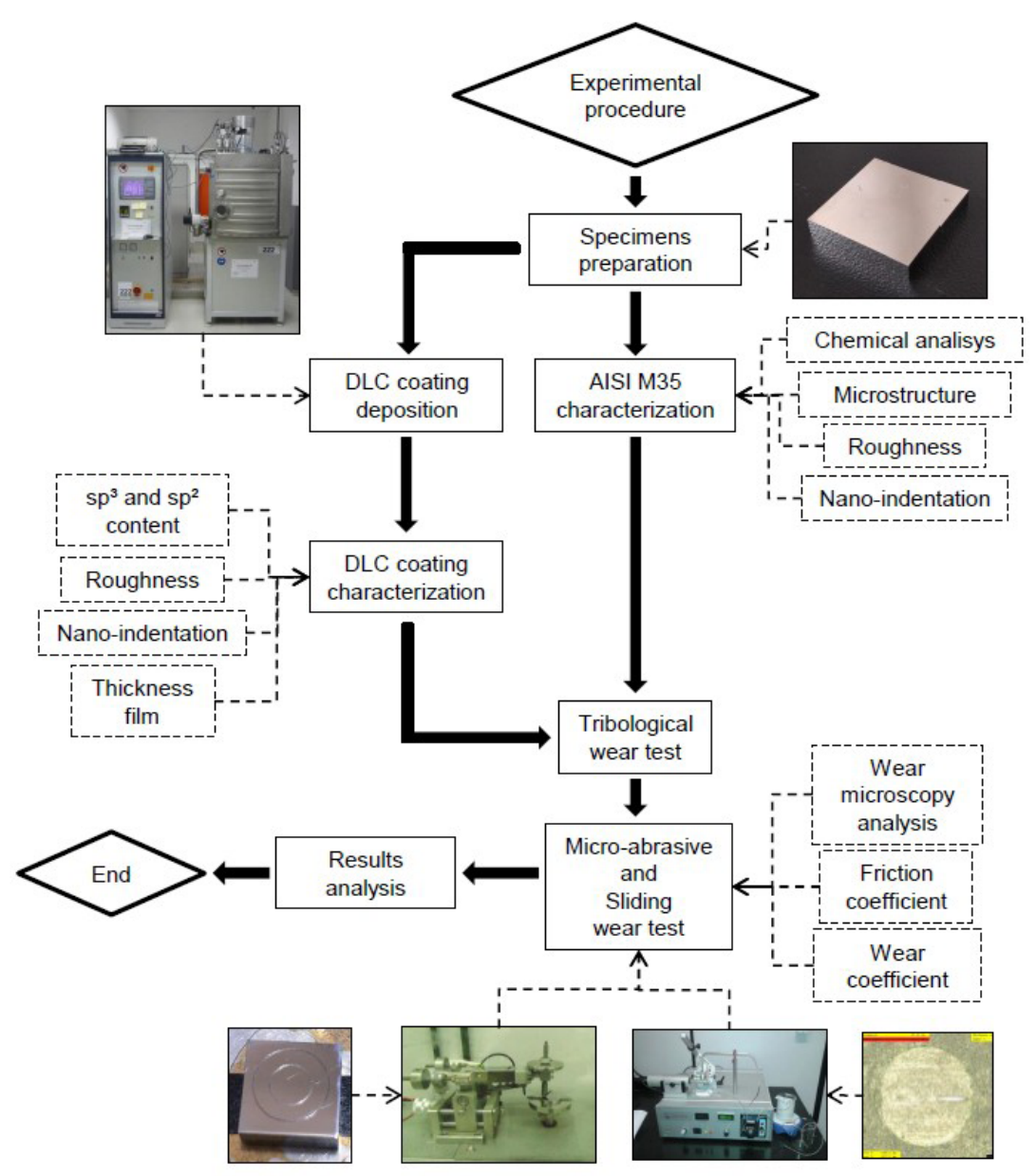

Figure 1. Methodological fluxogram followed on this study.

in hardness ${ }^{26}$. The presence of chromium improves the conditions of hardness and toughness, showing an average of $4.42 \%$ in the composition ${ }^{28}$. Molybdenum, with an average of $3.83 \%$, partially replaces tungsten and has the same type of double carbide with iron and carbon ${ }^{29}$. Vanadium increases the hot hardness, presenting an average of $1.39 \%$ and the tungsten element that improves shock resistance, hot hardness presented an average of 5.36\%. This alloying element added to the HSS provides ability to endure severe working conditions $\mathrm{s}^{30}$. The presence of the alloying elements promotes an increase in the mechanical resistance and the hardness in annealed steels. It happens due to the promotion of the hardening of the ferrite by a solid solution, by the increase of the number of fine carbide particles distributed in the structure produces a dispersion hardening. It happens because of the fine granulation of ferrite and the change in the shape of alloy carbides ${ }^{31}$.

The deposition of the non-hydrogenated DLC film was carried out by the magnetron sputtering process at a temperature of $150^{\circ} \mathrm{C}$ for three hours. The specimens went thru a cleaning process containing eleven steps, with some baths with degreasers, addition of solution and ultrasound. Then, the coating characterization procedure was started.

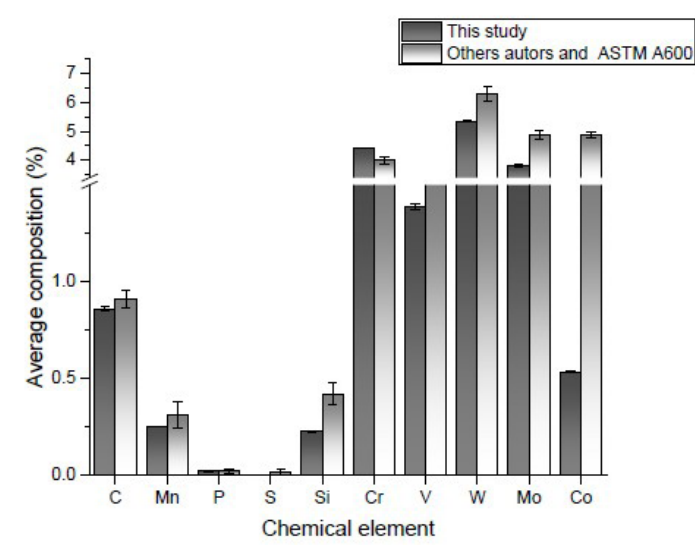

Figure 2. Chemical composition comparison of AISI M35 HSS.

The surface roughness of the AISI M35 substrate and the DLC film was measured using atomic force microscopy (AFM), on the AFM MPFP3D SAAsylum Research equipment. In the contact analysis mode, an Olympus silicon AC160TS 
probe scanned areas of $25 \mu \mathrm{m}^{2}, 100 \mu \mathrm{m}^{2}$ and $400 \mu \mathrm{m}^{2}$, with an average resonance frequency of $300 \mathrm{kHz}$ and an average spring constant of $26 \mathrm{~N} / \mathrm{m}$. The scanning mode of the probe was of the intermittent constant oscillatory type (Tapping) ${ }^{32}$, characterized by large amplitude vibrations and the signal is predominantly influenced by repulsive short-range interactions. Through the senility of the sensor in capturing the deflections of the probe during scanning over surfaces, two-dimensional and three-dimensional topographic images are recorded in the equipment's own software, making it possible to quantify the surfaces by means of the arithmetic mean roughness parameter $\left(\mathrm{R}_{\mathrm{a}}\right)$ at scale nano-metric ${ }^{33}$.

An AFM MPFP3D SAAsylum Research equipment was used in the contact mode to perform the nano-indentation on the materials, in the evaluation of the mechanical properties of hardness $(\mathrm{H})$ and Young's modulus $(\mathrm{E})$ based on the method presented by Oliver and ${ }^{34}$. In all, 36 indentations were performed with Berkovich indentator, varying the applied load between $50 \mu \mathrm{N}$ to $10,000 \mu \mathrm{N}$ in trapezoidal steps with a residence time of 5 seconds. The maximum depth of indentation was $180 \mathrm{~nm}$. Multiple loading and unloading are necessary to assess the reversibility of the deformation and thus make sure that the unloading data used for analysis is mainly elastic ${ }^{34}$. The hardness expresses the average pressure that the material will withstand under load, being calculated by the ratio between the maximum applied load and the projected area of the impression after plastic deformation on the surface ${ }^{13}$. Young's modulus is calculated from the projected area of elastic contact and material reversibility (elastic recovery) measured during unloading. In this case, it is also assumed that the area of elastic contact is equal to the projected area of the impression, measured by microscopy technique ${ }^{34}$.

Raman spectroscopy was used to estimate the contents of $\mathrm{sp}^{3}$ (like diamond) and $\mathrm{sp}^{2}$ (like graphite) hybridizations and thus classify the DLC, that is, being: a-C or ta-C based mainly on $\mathrm{sp}^{3}$ content. For this, the OLYMPUS BH-2 microscope was used with an argon laser (COHERENT INNOVA 70) operating with a wavelength $\lambda$ of $514.5 \mathrm{~nm}$ and powers of $700 \mathrm{~mW}$.

The tribological tests carried out in this study were the calowear and ball-on-disc sliding tests. The micro-abrasive wear test was performed according to the guidelines of ENV 1071 (EUROPEAN COMMITTEE FOR STANDARDIZATION, 2001). The equipment used was the Compact Calo tester CATc Anton Paar equipment, $25 \mathrm{~mm}$ diameter AISI 52100 steel ball frequently used in other studies ${ }^{1,22,35}$. A silicon carbide abrasive solution ( $\mathrm{SiC}-99.98 \%$ ) diluted $20 \%$ in ethylene glycol was used according to ${ }^{36}$, who mentions that it is a recommended choice due to the positive results obtained in other studies. From pre-tests performed, it was observed the satisfactory formation of the wear caps under constant parametric conditions of normal load in the value of $0.403 \mathrm{~N}$, rotation of the ball at $1000 \mathrm{rpm}$ in a contact time of 5 minutes. These values are similar to those used by ${ }^{21}$ (normal load) ${ }^{37}$, (rotation) and ${ }^{36}$ (test time). The generated craters were analyzed and measured using SEM and, finally, the average wear coefficient $\mathrm{k}\left(\mathrm{m}^{3} / \mathrm{N} . \mathrm{m}\right)$ of each material studied was calculated according to Archard's Equation 1:

$$
k=\frac{V}{L \times W}
$$

Where, $\mathrm{V}\left(\mathrm{m}^{3}\right)$ is the worn volume, $\mathrm{W}(\mathrm{N})$ is the normal load applied to the surface and $\mathrm{L}(\mathrm{m})$ is the sliding distance. Replacing the volume as a function of the outer diameter of the cap $\mathrm{b}(\mathrm{m})$ produced and the radius of the sphere $\mathrm{R}(\mathrm{m})$ used, the equation becomes (Equation 2):

$$
k=\frac{\pi \times b^{4}}{64 \times R \times L \times W}
$$

Finally, replacing as a function of the sliding time (min), the rotation $\mathrm{n}(\mathrm{rpm})$ and the radius $\mathrm{R}(\mathrm{m})$ of the sphere, the wear coefficient $\mathrm{k}$ is calculated by Equation $3^{38}$ :

$$
k=\frac{b^{4}}{128 \times R^{2} \times n \times t \times W}
$$

After performing the micro-abrasive test, the craters produced by the relative contact were analyzed and measured on the SEM to calculate the wear coefficient.

The ball-on-disc sliding tribological test was performed based on the ASTM G99 - 05 standard, with the objective of observing the friction coefficient behavior and the wear of the material surface/test body tribosystem. The equipment used was the Microtest SMT-A / 0100-MT / 60 / NI PLINT \& PARTNERS, also used by ${ }^{11}$, allocated in a laboratory with standardized air conditioning to perform tests at room temperature $\left(\approx 23^{\circ} \mathrm{C} \text { and } 45 \% \text { of relative humidity }\right)^{4,11,39}$. The tests were carried out in dry sliding ${ }^{39}$ in three different conditions for the evaluation of AISI M35 steel with and without DLC, as shown in Table 2, whose objective was to verify the friction behavior under load influences normal ${ }^{8}$ and the peripheral sliding speed. In each test, $6 \mathrm{~mm}$ diameter spherical bodies ${ }^{40}$ made of AISI 52100 steel $(0.98 \% \mathrm{C}$ and $1.40 \% \mathrm{Cr}, 63 \mathrm{HRC})^{8}$ were used. Then, the wear tracks were analyzed in the SEM and the friction coefficient curves were plotted through the acquisition of data from the RS232 interface

\begin{tabular}{|c|c|c|c|c|c|}
\hline Material & Test & Speed (rpm) & Load $(\mathrm{N})$ & Track radius $(\mathrm{mm})$ & Sliding distance $(\mathrm{m})$ \\
\hline \multirow{3}{*}{ AISI M35 } & 1 & 400 & 2 & 2.5 & 44 \\
\hline & 2 & 200 & 4 & 5.0 & 30 \\
\hline & 3 & 300 & 6 & 7.5 & 30 \\
\hline \multirow{3}{*}{$\begin{array}{l}\text { AISI M35 with } \\
\text { DLC }\end{array}$} & 1 & 500 & 2 & 3.7 & 44 \\
\hline & 2 & 300 & 4 & 5.0 & 30 \\
\hline & 3 & 200 & 6 & 3.0 & 30 \\
\hline
\end{tabular}
coupled to the tribometer.

Table 2. Ball-on-disc sliding wear test conditions 


\section{Results and Discussion}

\subsection{Materials characterization}

\subsubsection{Microstructural analysis of the AISI M35 HSS}

The steels used to manufacture cutting tools can be considered as martensitic steels containing alloying elements. Martensite is a supersaturated carbon phase and constituent in steel with a tetragonal structure with a centered face. It represents the microstructural matrix and is responsible for the primary hardening of $\mathrm{HSS}^{41}$. In Figure 3, the martensitic matrix is observed in the darkest shade of the microstructure. Molybdenum, tungsten, vanadium and chromium are alloying elements responsible for the secondary hardening of steels ${ }^{42}$. First, there is an increase in hardenability due to the increased stability of the austenitic phase. Then, there is a coalescence control of the austenitic grains that later results in the martensitic matrix refinement. Finally, these elements promote the precipitation of carbides, which can be observed in the microstructure in a lighter shade. The carbides are dispersed and in different sizes. The more refined precipitates have elliptical and globular morphology. In the analysis by ${ }^{24}$ on AISI M35 HSS, carbides of different sizes were also identified. The primary carbides, formed after quenching, were rich in vanadium, molybdenum and tungsten with coarse morphology and distributed heterogeneously. Secondary carbides, formed after tempering, were refined and were evenly distributed. The EDS analysis shows that the microstructure predominates in iron, carbon and tungsten, the first two elements are the basic ones for the composition of the steel itself and the martensite. Then, the presence of tungsten shows the formation of carbides in the microstructure. The combination of these three elements can lead to the precipitation of the $\mathrm{Fe}_{3} \mathrm{~W}_{3} \mathrm{C}$ carbide, also called $\mathrm{M}_{6} \mathrm{C}^{26}$. used the AISI M35 to develop a computational study of planning the microstructure of HSS. The microstructural analysis, by SEM, identified carbides in lighter shades dispersed in the matrix. According to the authors, the AISI M35 has a predominant microstructure of $\mathrm{M}_{6} \mathrm{C}$ carbides ${ }^{30}$. cite that this carbide has globular morphology.

The presence of vanadium and chromium in the analysis, however in low intensity showed by the EDS, also exposes that the microstructure may be constituted by vanadium (MC) and chromium $\left(\mathrm{M}_{23} \mathrm{C}_{6}\right)$ carbides $^{25}$. found $\mathrm{MC}$ carbides in AISI M35 steel, but in a smaller volume $(0.9 \%)$ when compared to $\mathrm{M}_{6} \mathrm{C}(7.8 \%)^{29}$. also found carbides $\mathrm{MC}$ (rich in vanadium) and $\mathrm{M}_{6} \mathrm{C}$ (rich in molybdenum and tungsten). In addition, $\mathrm{M}_{23} \mathrm{C}_{6}$ carbide was also found in the microstructure, which is rich in chromium.

\subsubsection{Deposition and classification of the DLC coating}

The AFM images in Figure 4 confirms that the measurement area of the total coating thickness lies within a square of $100 \mu^{2}$. The thickness of the DLC film applied on a HSS substrate showed uniformity on the substrate, containing small flaws in the entire deposited region. At various points, the thickness values varied from $0.47 \mu \mathrm{m}$ up to $1.69 \mu \mathrm{m}$. The average thickness was $1.027 \pm 0.321 \mu \mathrm{m}$. The result is within the thickness range observed in other studies, where the DLC coatings deposited by PVD processes have thicknesses between $0.03 \mu \mathrm{m}$ and $2.0 \mu \mathrm{m}$ approximately ${ }^{43}$. obtained a $1.45 \mu \mathrm{m}$ thick DLC film deposited on a sample of DIN 1.4452 steel $^{23}$. presented DLC samples deposited on silicon substrates by the conventional sputtering process whose thickness varied between $0.5 \mu \mathrm{m}$ and $0.9 \mu \mathrm{m}^{39}$. deposited the DLC on the AISI M2 HSS substrate by the sputtering process, obtaining a thickness of $1.68 \mu \mathrm{m}^{5}$. performed the DLC deposition on a HSS commercially used for the manufacture of drills by means of the PVD process at a constant temperature of $200^{\circ} \mathrm{C}$, varying only the laser fluence. The authors found that in all deposition conditions, the film had a homogeneous thickness throughout the entire cross section of the samples. Thicknesses varied between $0.050 \mu \mathrm{m}$ and $0.100 \mu \mathrm{m}^{44}$. obtained DLC thicknesses (class a-C: $\mathrm{H}$ ) between $0.910 \mu \mathrm{m}$ and $0.925 \mu \mathrm{m}$ deposited on the carburized and lapped SCM415 substrates by means of unbalanced magnetron sputtering. In addition, it is observed in the AFM images that the morphology of the DLC appears to consist of particles similar to nano-spheres. In the study by $^{4}$, the DLC microstructure deposited by pulsed laser deposition at a temperature of $100^{\circ} \mathrm{C}$ was constituted by spherical nano-particles with $0.010 \mu \mathrm{m}$ in diameter. The authors observed a homogeneous film thickness of approximately $0.270 \mu \mathrm{m}$.
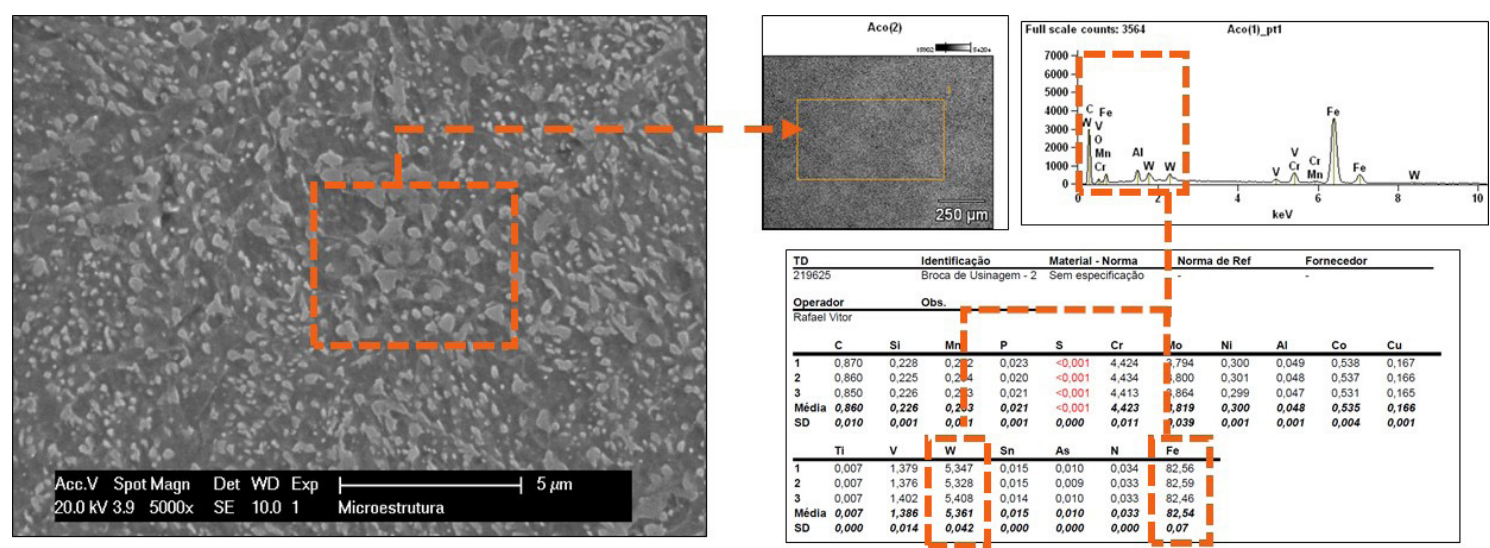

Figure 3. MEV analysis of AISI M35 microstructure. 

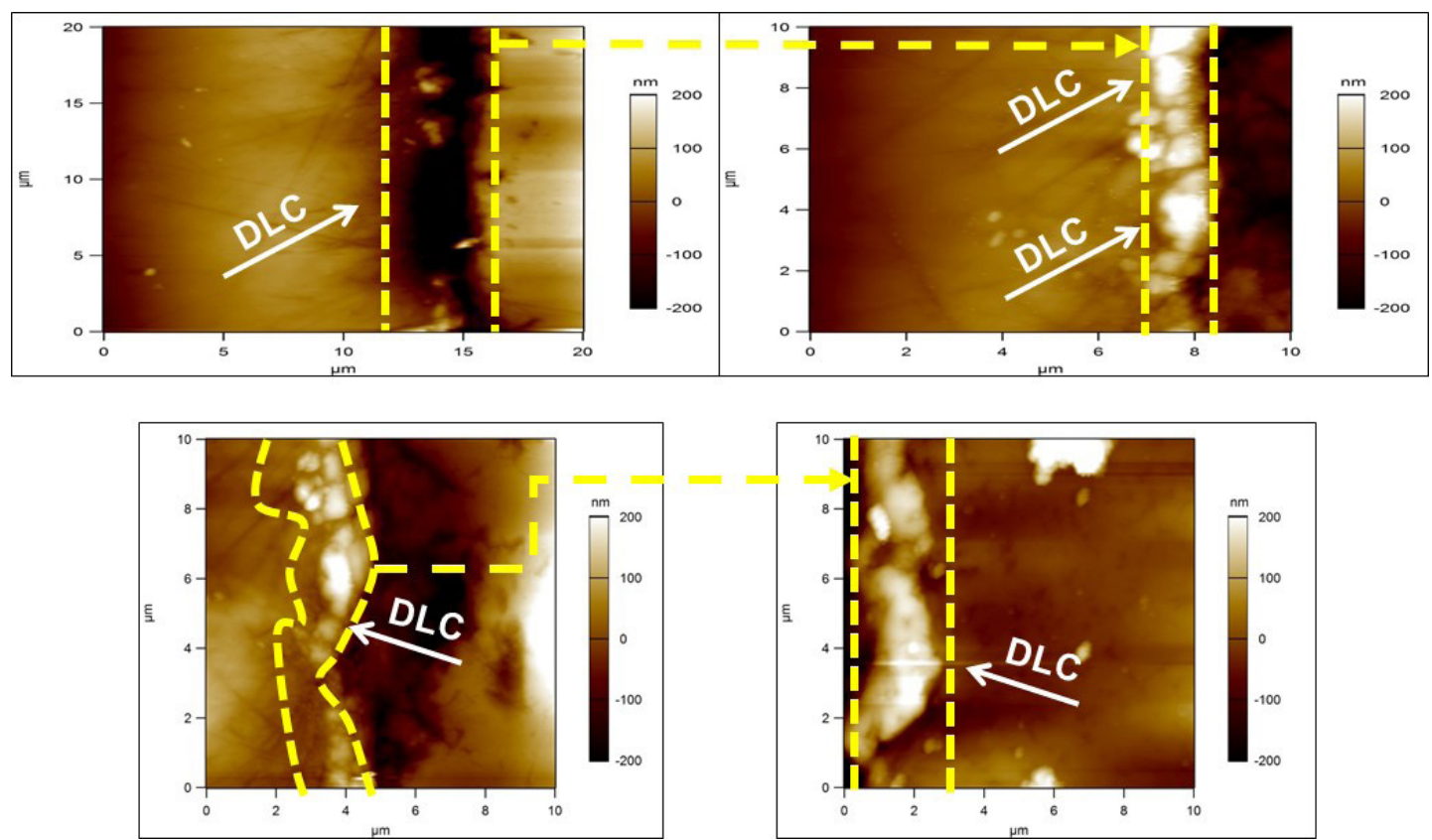

Figure 4. Thickness measurement of the DLC coating deposited on the AISI M35 HSS.

In the case of high-speed steel, PVD processes are fundamental for the application of coatings without significant changes in the microstructure due to the effect of the deposition temperature. Therefore, these materials are not recommended to be subjected to CVD deposition processes, whose temperatures exceed $500^{\circ} \mathrm{C}$. Depositing DLC on HSS is an alternative to add properties of graphite and majorly the diamond similar, for example, to the synthetic diamond PCD, deposited by CVD. However, the DLC obtained by the PVD process generally does not show good adhesion to the substrate due to the residual stresses resulting from the differences in thermal expansion coefficients between the DLC coating and the substrate. Generally, the addition of an interfacial coating alleviates the adhesion problem. According to ${ }^{45}$, the DLC cannot be deposited directly on steel substrate because the carbon in the graphite (target material) diffuses into steel initiating a catalytic effect that leads to the formation of graphite. These factors delay the nucleation of the film and impair the adhesion of the film ${ }^{43}$. used titanium as the adhesion interface ${ }^{39}$. used a Ti/TiN/TiCN film that was deposited to improve the adhesion between the DLC and the substrate ${ }^{5}$. deposited a silicon film at the interface ${ }^{44 \text { and } 46}$. used a $\mathrm{Cr} / \mathrm{C}$ interlayer approximately $0.47 \mu \mathrm{m}$ thick at the substrate adhesion interface. The film thickness is also a limiting factor for the DLC application. The increase in thickness favors the mechanical resistance of the coating, however, it reduces its adhesiveness on the substrate ${ }^{5}$.

Figure 5 shows the normalized Raman spectrum of the coating. Raman spectroscopy has been used extensively to detect the structure of carbon and diamond films $\mathrm{s}^{47}$, in addition of being an efficient non-destructive characterization method ${ }^{48}$. The Gauss deconvolution features five curves in the Raman shift range between $700 \mathrm{~cm}^{-1}$ and $1900 \mathrm{~cm}^{-146}$. The highest intensity peaks between $1300 \mathrm{~cm}^{-1}$ and $1700 \mathrm{~cm}^{-1}$ are related to the main characterization bands of DLC coatings, because

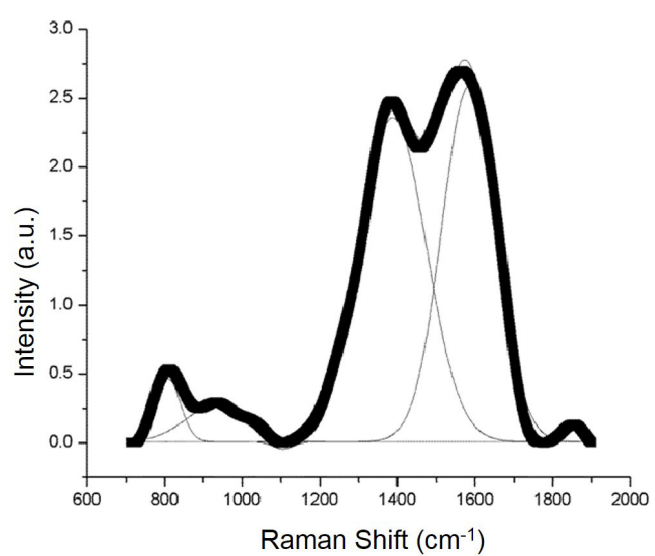

Figure 5. Results from Raman spectrum of the studied DLC coating.

through them it is possible to estimate the contents of $\mathrm{sp}^{3}$ and $\mathrm{sp}^{2}$ hybridizations. They are then bands $\mathrm{D}$ and $\mathrm{G}$, which are generally centered around $1360 \mathrm{~cm}^{-1}$ and $1580 \mathrm{~cm}^{-1}$ respectively ${ }^{46}$. The deconvolution results are shown in Table 3 with a determination coefficient of 0.996 . The bands D and G are located at $1388.160 \mathrm{~cm}^{-1}$ and $1584.631 \mathrm{~cm}^{-1}$ respectively. The $\mathrm{I}_{\mathrm{D}} / \mathrm{I}_{\mathrm{G}}$ ratio equal to 0.913 refers to the intensities of the bands in terms of peak height as adopted in the study by ${ }^{3}$. Based on the carbon amorphization trajectory presented by the authors, the coating is comprised of Stage 2 (nanocrystalline graphite to a-C).

\subsubsection{Roughness analysis}

One of the key parameters associated with the coating deposition is the substrate, which is a consequence of material 
and surface preparation. As for the material, the adhesion of the coating will be better the greater its metallurgical compatibility with the substrate is. The adhesion of DLC to metallic substrates usually generates failures, results are improved by inserting an intermediate layer of silicon ${ }^{49}$, titanium ${ }^{43}$ or chromium ${ }^{44}$, for example. The surface preparation starts with the machining process that will determine the surface roughness and, therefore, the adhesion with the coating ${ }^{11}$. Polishing is often used to produce surfaces with low roughness, generating an interface with a greater real contact area. The cleaning of the substrate surface, preparation and substrate modification processes are important for the adhesion of any type of thin film. Contaminating layers that prevent a chemical interaction between the deposition of the coating on the substrate must be eliminated ${ }^{50}$. The surface topography of the steel substrate shown in Figure 6a is characterized by longitudinal traces similar to "striations" abrasive action form of the polycrystalline grains $(0.5 \mu \mathrm{m}$ to $3 \mu \mathrm{m}$ in size) of the micro-crystalline aluminum oxide wheel $\left(\mathrm{Al}_{2} \mathrm{O}_{3} \mathrm{MC}\right)$. In spite of being classified as of undefined geometry, it is observed a tool that as feed marks left on the surfaces are regular roughness (peaks and valleys), containing some defects as indicated in yellow. The mentioned regularity is confirmed with the results provided in Table 4, where the roughness varied between $13 \mathrm{~nm}$ to $16 \mathrm{~nm}$ in the three AFM analysis areas ${ }^{11}$. obtained a roughness of approximately $10 \mathrm{~nm}$ on the polished surface of AISI M2 HSS for coating deposition $^{23}$. also published the same value in the study during the substrate preparation for DLC deposition. The effect of substrate roughness on the adhesion of coatings is still widely discussed. Rough or textured surfaces (micro-dimple) can improve adhesion due to the mechanical anchoring effect of roughness. However, in the case of thin films such as DLC, these surfaces may not be advantageous. A small thickness of the film may be insufficient to cover all roughness, affecting a heterogeneous coating.

Figure $6 \mathrm{~b}$ shows the DLC-coated surface topography. It is clear that the surface was modified by the deposition process, where the feed marks of the machining process were completely covered by the DLC. The topography is

Table 3. Results from Raman spectrum deconvolution of DLC coating

\begin{tabular}{ccccc}
\hline Fit Peak & Raman shift $\left(\mathrm{cm}^{-1}\right)$ & Peak intensity (a.u.) & $\mathrm{I}_{\mathrm{D}} / \mathrm{I}_{\mathrm{G}}$ ratio & $\mathrm{R}_{\text {adjust }}^{2}$ \\
\hline D Band & 1388.160 & 2.350 & 0.913 & 0.996 \\
\hline G Band & 1584.631 & 2.575 & & 0.96 \\
\hline
\end{tabular}

Table 4. Average surface roughness $\mathrm{R}_{\mathrm{a}}$

\begin{tabular}{cccc}
\hline \multirow{2}{*}{ Surface } & \multicolumn{3}{c}{ AFM analysis area $\left(\mu \mathrm{m}^{2}\right)$} \\
\cline { 2 - 4 } & 25 & 100 & 400 \\
\hline $\mathrm{R}_{\mathrm{a}}(\mathrm{nm})$ - AISI M35 & $14.0 \pm 0.5$ & $13.1 \pm 0.28$ & $16.3 \pm 0.5$ \\
\hline $\mathrm{R}_{\mathrm{a}}(\mathrm{nm})$ - AISI M35 with DLC & $48.5 \pm 4.8$ & $72.8 \pm 7.7$ & $100 \pm 14.1$ \\
\hline
\end{tabular}

(a) $\mathrm{R}_{\mathrm{a}}$ Analysis Without DLC Film
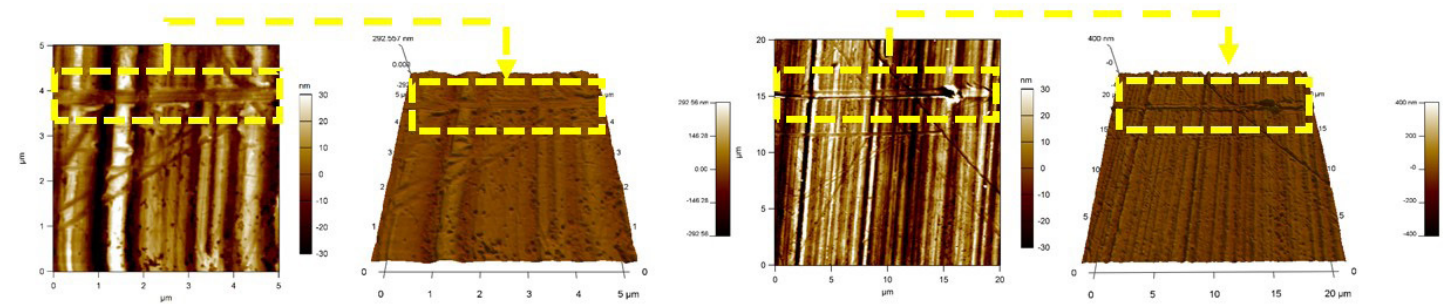

(b) $\mathrm{R}_{\mathrm{a}}$ Analysis With DLC Film
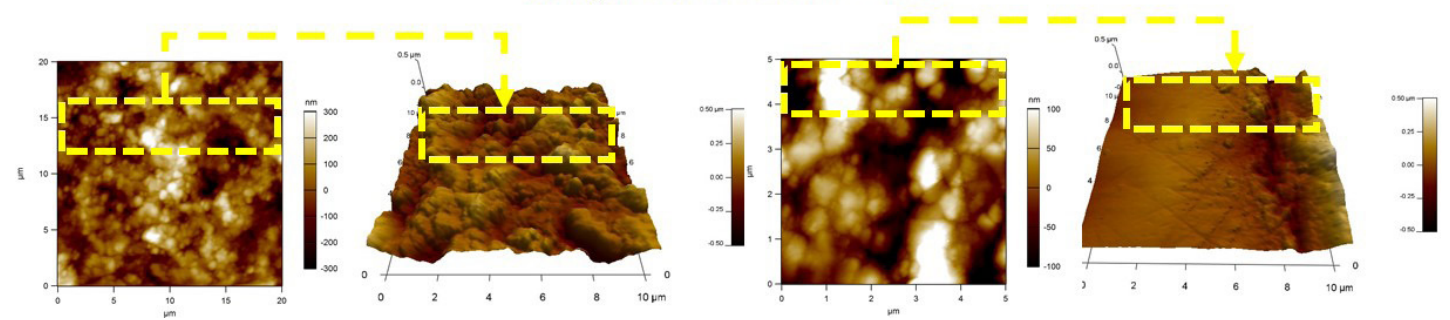

Figure 6. $\mathrm{R}_{\mathrm{a}}$ roughness assessment, before (a) and after (b) deposition of the DLC coating. 
characterized by the presence of several irregularities, a very rugged topography. In fact, it refers to the term "sputtering" of the PVD process, as these irregularities can represent random piles and overlaps of atomic carbon layers ${ }^{51} .{ }^{40}$ reported that the deposition process modifies and increases the surface roughness. In the study ${ }^{52}$, the DLC application on a NBR (nitrile butadiene rubber) substrate by magnetron sputtering process promoted the roughness reduction from $274.35 \mathrm{~nm}$ to $41.03 \mathrm{~nm}$. According to the authors, this reduction occurred due to the filling of the roughness and defects of the substrate by carbon atoms. Comparing to the topography of steel (Figure 6a), it is already expected that the average roughness is higher. The result is then confirmed in Table 4. The average roughness varied from $48.5 \mathrm{~nm}$ to $100 \mathrm{~nm}$ in the analyzed areas. These results were $71 \%, 82 \%$ and $84 \%$ higher in relation to the steel roughness, respectively in the areas of $25 \mu \mathrm{m}^{2}, 100 \mu \mathrm{m}^{2}$ and $400 \mu \mathrm{m}^{2}$.

The analysis through AFM shows that the deposition is inherent to the process parameters. Mainly, attention was drawn to the surface topography aspect, which refers to the conclusion that the deposition was not entirely homogeneous on the surface ${ }^{2}$ and 53 . reported that the DLC surface is dense, compact and free from defects ${ }^{5}$. obtained DLC coatings with roughness ranging from $0.2 \mathrm{~nm}$ to $0.4 \mathrm{~nm}$ deposited on silicon substrates by the PVD process ${ }^{7}$. obtained the coating with even lower roughness by the same deposition process, on an atomic scale $(0.11 \pm 0.03 \mathrm{~nm})$. In the study ${ }^{43}$, the roughness of the DLC coatings varied between approximately $30 \mathrm{~nm}$ and $140 \mu \mathrm{m}$. In the pin-on-disc test, the friction coefficient did not show any tendency of change in relation to the roughness. However, the authors mentioned that the correlation between roughness and friction coefficient is negative, that is, rough surfaces provide a lower friction coefficient. The actual contact area becomes smaller when compared to a less rough surface, which consequently reduces the friction coefficient. However, it must be considered that if the contact area does not support the load, then there will be a break in the surface roughness. Wear particles will be formed that can increase the friction coefficient and promote severe wear ${ }^{2}$. However, in the case of DLC, the increase in roughness shown in Figure $6 \mathrm{~b}$ and Table 4 is still not enough to state that its performance will be negative, as this film has the properties of diamond and graphite. In a sliding tribological system, a layer of graphite is formed by the wear of the DLC and as a consequence, the friction coefficient reduces ${ }^{40}$. The result presented in Raman spectroscopy (Table 3) has already indicated that the coating is the majority in content $\mathrm{sp}^{2}$, graphite, therefore, the statements mentioned can be proven in the tribological tests presented below.

\subsubsection{Nano-indentation}

In Figure 7, the results of the nano-indentation test performed in the AISI M35 HSS with and without DLC coating applied to the substrate are presented. Nano-hardness and Young's modulus were determined by the method of Oliver and Pharr, whose maximum indentation depth did not exceed $17 \%$ of the total coating thickness $(1.027 \pm 0.321 \mu \mathrm{m})$. The hardness, which represents the resistance to localized plastic deformation ${ }^{11}$, is obtained by the load/displacement/ time data after the material elastic response ${ }^{54}$. The Young's

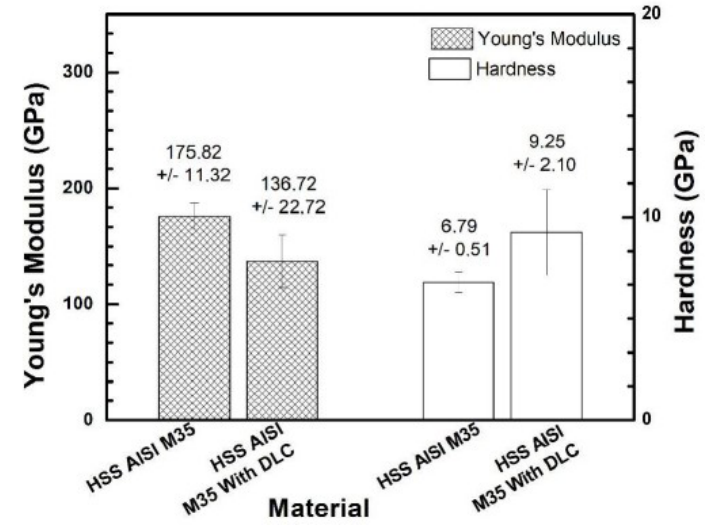

Figure 7. Results of nano-hardness and Young's modulus of AISI M35 HSS and DLC coating.

modulus represents the interatomic bonding force responsible for elastic deformation, which is calculated as a function of the elastic recovery of the material after unloading. For the film hardness determination, it is roughly defined that the referred hardness corresponds to that observed in the depth equivalent to $10 \%$ of the film thickness ${ }^{55}$. As shown, the surface hardness of the DLC was $9.25 \pm 2.10 \mathrm{GPa}$, and as expected, it was greater than the hardness of the AISI M35 steel, 6.79 $\pm 0.51 \mathrm{GPa}$. The DLC film deposited by sputtering by ${ }^{39}$ showed a slightly higher surface hardness of $12.9 \mathrm{GPa}$. The presence of diamond-like carbon in the coating structure contributes to its hardness ${ }^{56}$, since diamond is the hardest material found so far. The $\mathrm{sp}^{3}$ hybridizations constitute the cubic crystalline structure of strong covalent bonds with the known angle of $109^{\circ} 28^{\prime}$, forming an ABCABC type atomic stack ${ }^{57,58}$. However, the analyzed DLC consists mainly of carbon similar to graphite $\left(\mathrm{I}_{\mathrm{D}} / \mathrm{I}_{\mathrm{G}}\right.$ ratio shown in Table 3) whose two-dimensional hexagonal (plane) crystalline structure is strongly bonded, one atom to three other atoms. A free orbital is located in the plane perpendicular to the others, and is susceptible to form a secondary bond (Van der Waals) with other atoms, forming an ABABAB-type stack $^{57-59}$. Such stacking explains why graphite is considered a solid lubricant: Van der Waals secondary connections between hexagonal planes result in low shear strength - this is an important property of solid lubricants - for example, when a load parallel to the planes is applied, then there is a sliding of adjacent planes. On the other hand, if this load is applied perpendicular to the planes, there will be a greater material resistance due to the performance of the hexagonal structure of covalent bonds. Therefore, it is assumed that the graphite itself can also contribute to the resistance to localized plastic deformation imposed by indentation. As for steel, the hardness result was lower when compared to the result by $^{29}$ who obtained the value of $11.7 \pm 0.4 \mathrm{GPa}$ (on martensite matrix). One of the possible causes of this difference may be related to the low cobalt content measured in the chemical composition, as this element contributes to the nucleation of $\mathrm{M}_{2} \mathrm{C}$ carbides responsible for the secondary hardening of the microstructure ${ }^{60}$.

Regarding Young's modulus, the result was contrary to what was observed in nano-hardness. The steel presented greater 
rigidity $(175 \pm 11.32 \mathrm{GPa})$ than the coating $(136.72 \pm 22.72 \mathrm{GPa})$. Analyzing the values individually, it can be compared with other studies whose mechanical properties were relatively similar. The results obtained by ${ }^{23}$ showed that Young's modulus has a positive correlation with the content of $\mathrm{sp}^{3}$ hybridizations. The DLC containing less than $20 \% \mathrm{sp}^{3}$ showed Young's modulus between $100 \mathrm{GPa}$ and $200 \mathrm{GPa}^{29}$. mentioned that Young's modulus of steels is generally approximately $210 \mathrm{GPa}$. In Figure 7, it can be seen that hardness and rigidity do not necessarily obey a positive correlation, although this result is contradictory, for example, to ${ }^{61}$ who investigated the effect of DLC nickel doping at different percentage levels. Nano-indentation results showed that the hardness and Young's modulus followed the same trend: increase with the addition of nickel. The authors also mentioned that the stiffness, which is correlated to the Young's modulus, varies proportionally with the hardness of the coating $^{62}$. reported that the hardness and Young's modulus have a strong dependence on chemical composition and density of coatings. The tests showed a good correlation between density and Young's modulus. The results showed that the presence of amorphous content reduces the density of the coating, and thus also the rigidity of the coating. Following this line of analysis of the relationship between stiffness and density, the DLC deposited by PVD process in the studies by ${ }^{5 \text { and }} 7$ showed a density of $1.77 \mathrm{~g} / \mathrm{cm}^{3}$ and $2.9 \mathrm{~g} / \mathrm{cm}^{3}$ respectively. The density of HSS is usually close to $8 \mathrm{~g} / \mathrm{cm}^{3}, 71 \%$ higher when compared to the average value obtained by the two mentioned authors. Based on that, the statement by ${ }^{62}$ mentioned above may be correct, however, further studies should be carried out to obtain more reliable conclusions regarding the relationship between hardness and Young's modulus.

Considering the arithmetic mean value added to the measurement uncertainty, there is a difference of 5.06 GPa between the minimum and maximum end of the Young's modulus of the DLC and of the AISI M35 HSS, respectively (Figure 7). Therefore, there is no values overlapping, which leads to assume that the difference between Young's modulus is significant. Regarding nano-hardness, the same assumption can be made, since there was a difference of 1.95 GPa between the minimum extreme value of the DLC and the maximum extreme value of the stee ${ }^{11}$. performed nano-indentations in two coatings, $\mathrm{AlCrN}$ and TiAlN, finding no significant differences in nano-hardness and Young's modulus. However, the authors calculated the $\mathrm{H} / \mathrm{E}$ ratio (Hardness/Young's modulus) for both coatings and classified $\mathrm{AlCrN}$ as being probably more resistant to wear due to the higher $\mathrm{H} / \mathrm{E}$ ratio ( 0.02 greater than TiAlN). A higher value of this ratio means that the coating has a higher hardness than Young's modulus. Applying this analysis methodology, the $\mathrm{H} / \mathrm{E}$ ratio of the DLC is $0.07 \pm 0.02$ and that of AISI M35 steel is $0.04 \pm 0.00$. Through the combined uncertainty related to individual measurement uncertainties, the results show a significant difference, indicating that DLC may have better wear resistance when compared to steel ${ }^{63}$.

\subsection{Tribological experiments}

\subsubsection{Micro-abrasive wear test}

The micro-abrasive wear test was the first tribological test performed to evaluate the coating performance compared to the substrate surface. The test parameters were kept constant with the sole objective of observing the resistance to abrasive wear during the five minutes of sliding. Both optical and scanning electron microscopy were used to measure the diameters of the wear caps produced on the surfaces. As in other studies, measurement uncertainties are often mentioned in the analysis of the results, as the craters produced do not always have a circumference shape, in top view, the edges are not well defined ${ }^{21}$. It is also worth mentioning that microscopy is a fundamental technique for the "wear impression" analysis generated on the surface, because the craters identification is due to the difference in tone of the SEM image as a function of the differences in electron penetration depth. The lighter shade is the result of the greater depth (energy) of penetration, applied for the observation of regions formed by chemical elements with a lower atomic number. The darker shade refers to the shallower depth of penetration, applied to chemical elements with a greater atomic number (heavier elements).

Figure 8 shows the craters produced on the analyzed surfaces. The sliding time was enough for the complete removal of the coating and then reaching the substrate. The EDS analyzes confirms this statement, that is, the majority of iron, carbon and tungsten are present in the analyzed areas, chemical elements present in the composition of AISI M35 HSS as discussed in Figure 3. On both surfaces, the final wear was predominantly characterized by the removal of material in the direction of the sphere sliding, presented by the presence of scratches/grooves resulting from the combined abrasive action (grooving) of the toughest bodies of the tribosystem: silicon carbide ( $\mathrm{SiC})$ and the sphere ${ }^{35}$. This combined action refers to three-body abrasion and two-body abrasion. In three-body abrasion, the rolling and sliding of abrasive particles of undefined geometry generate localized indentations and scratches on the surface, as if they were small craters. However, the path taken by these particles at the interface is random. Thus, the presence of scratches/grooves in the presented craters is more related to the two-body abrasion wear, where the roughness of the sphere surface slides in a defined orientation on the static surface, causing the groove and the removal of material. Similar analyzes were performed in the studies by 35 and 64 . The union of different materials, substrate/DLC interface, is evidenced by the edges of the craters. It is observed when reaching this interface, possible changes in the tribosystem can occur by changing, for example, the friction coefficient. The edges are not homogeneous, which may be related to the sphere instability during sliding. The opposite is observed in the craters generated on the uncoated surface, where the edges were more homogeneous ${ }^{1}$. investigated the influence of DLC deposited on AISI H13 steel during the microabrasive test. According to the authors, in the presence of DLC, the three-body abrasion wear is predominant, where the abrasive particles gradually remove the coating. At this stage, abrasive adhesion is not observed due to the chemical inertia of the DLC. But once the coating is completely removed, the two-body abrasion wear comes into action together, modifying the tribosystem (adhesion and abrasion) and increasing the wear rate. 


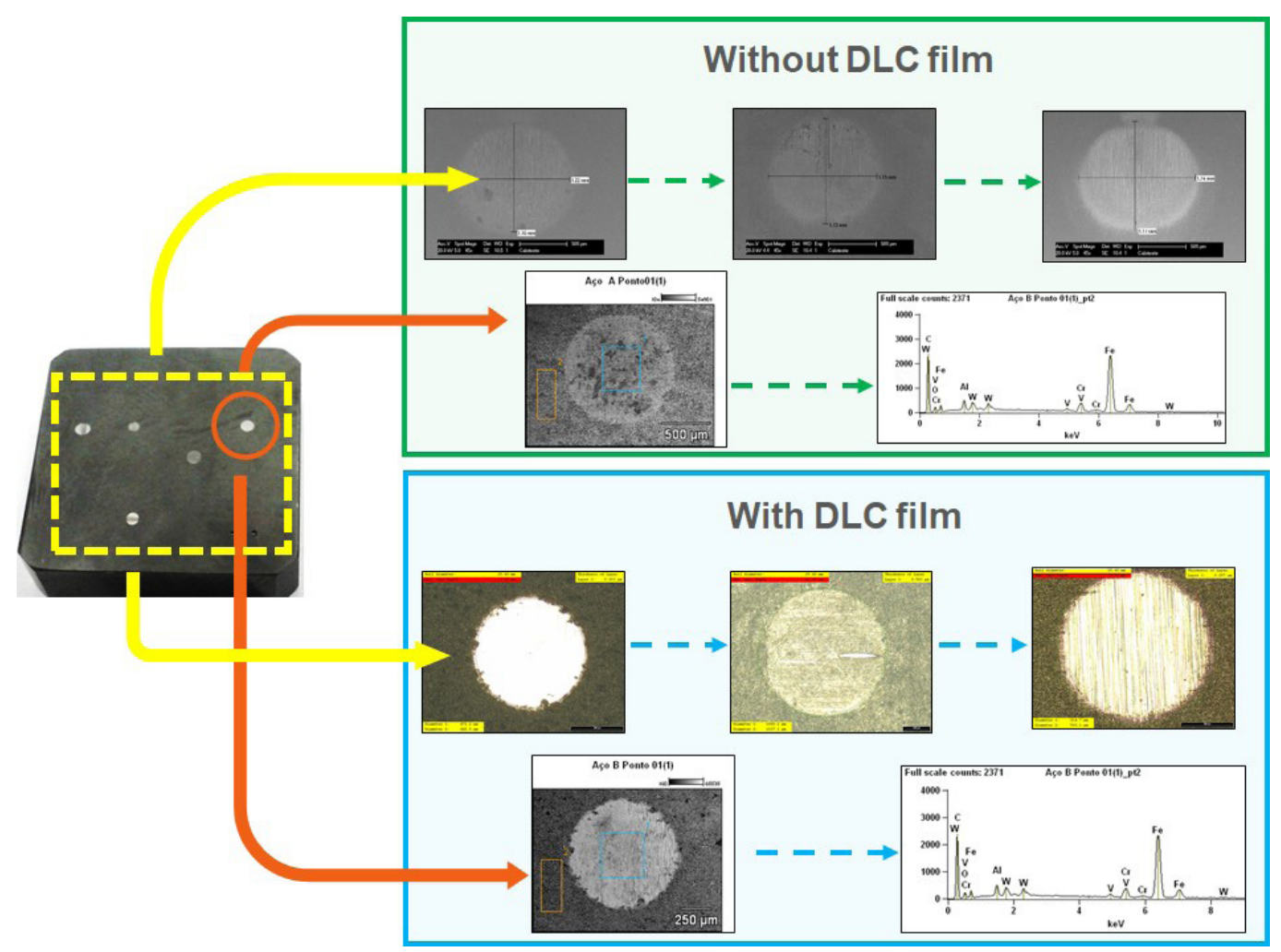

Figure 8. Craters wear analysed by SEM.

The evidence in which it is possible to state that the DLC provided a reduction in wear was the measured craters diameter, $1.64 \pm 0.07 \mathrm{~mm}$ and $1.20 \pm 0.04 \mathrm{~mm}$ for uncoated and coated AISI M35 HSS, respectively, corresponding to a $27 \%$ reduction. The diameter is indicative of the wear magnitude, as it is related to the penetration depth of the sphere reached from the contact interface. Based on the Archard equation (Equation 1 and Equation 3), it can be said that the result found was expected since the surface wear volume is inversely proportional to its hardness. Therefore, the results discussed about the nano-indentation (Figure 7) were confirmed in the calowear: (1) the greater nano-hardness of the DLC compared to AISI M35 provides resistance to abrasive wear and (2) the $\mathrm{H} / \mathrm{E}$ ratio mentioned by ${ }^{11}$, whose DLC showed the highest value also showed the expected correlation. Regarding hardness, a result of the same trend was found by ${ }^{1}$ who obtained a $44 \%$ and $55 \%$ reduction in the diameters of the wear craters produced in the AISI H13 steel samples coated with $24 \mathrm{GPa}$ and $33 \mathrm{GPa}$ nano-hardness, respectively, compared to the uncoated sample. Through Equation 3 the results are presented in terms of the wear coefficient $\mathrm{k}$ in Figure 9.

A $71 \%$ reduction was obtained on the DLC-coated surface $\left(\mathrm{k}=5.27 \mathrm{E}-14 \pm 6.55 \mathrm{E}-15 \mathrm{~m}^{3} / \mathrm{N} . \mathrm{m}\right)$ in relation to the AISI M35 substrate $\left(\mathrm{k}=1.83 \mathrm{E}-13 \pm 3.25 \mathrm{E}-14 \mathrm{~m}^{3} / \mathrm{N} . \mathrm{m}\right)$. The graphical analysis reinforces the previous discussion about wear caps, showing that the coating application can provide improvements in tribological properties, in this case, resistance to abrasive wear ${ }^{1,21,65}$. also mentioned expressive differences in wear reduction when applying the DLC. It is also worth mentioning

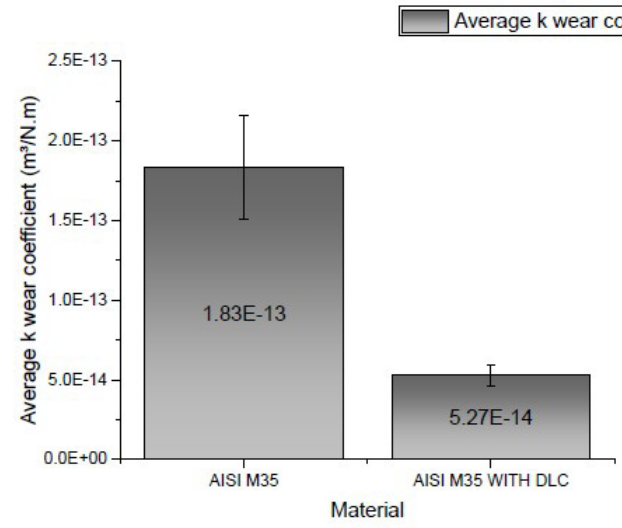

Figure 9. Wear coefficient assessed on the AISI M35 HSS substrate with and without DLC coating.

that probably the mechanical and microstructural properties presented by the coating may have masked the possible effects of roughness on tribological behavior. Therefore, it was not possible to say whether the increase in roughness after the deposition of the film (Figure $6 \mathrm{~b}$ and Table 4) provided benefits or harms. As an example ${ }^{21}$, compared the resistance to micro-abrasive wear between titanium nitride (TiN) and DLC coatings deposited on AISI M2 steel. The roughness measured by AFM was $90 \mathrm{~nm}$ and $62 \mathrm{~nm}$, respectively. In analyzing the results, the authors mentioned that the roughness did not significantly influence the wear resistance. 


\subsubsection{Ball-on-disc test}

Reducing friction and adhesion between surfaces that are in a sliding contact is an effective way to mitigate energy losses and increase the efficiency of mechanical components and cutting tools, that can be applied in various areas of engineering. For this purpose it is very important to improve the tribological characteristics of steel, especially the friction coefficient. The ball-on-disc test is an alternative to validate and understand the tribological behavior of materials. Through the friction curves and the wear tracks analysis it is possible to understand the magnitude of metallurgical compatibility of the materials, the dominant wear mechanisms, the influence of coatings and lubricants, the effects of loading, the peripheral speed, the environmental conditions, among others. Figure 10 shows the SEM analysis of the AISI M35 HSS surface with and without DLC. This procedure was carried out to verify the wear produced in the sliding tracks. In the tracks generated on the DLC film there was less deformation when compared to the uncoated substrate.

The friction coefficient measured during the ball-ondisc test is shown in Figure 11. Normal load parameters, rotation and distance covered were modified according to Table 2 presented above in order to assess the behavior of uncoated and DLC coated steel. Wear tracks with $2.5 \mathrm{~mm}$, $5.0 \mathrm{~mm}$ and $7.5 \mathrm{~mm}$ radius were produced on the uncoated surface. On the surface coated with DLC, tracks with $3.0 \mathrm{~mm}$, $3.7 \mathrm{~mm}$ and $5.0 \mathrm{~mm}$ radius were produced. In a general approach of the results, it is observed that the deposition of the DLC promoted changes in the behavior of the tribosystem that were reflected in the friction coefficient: increased stability and reduced magnitude.

In tests 1 and 2 (Figure 11a and 11b) with loads of 2 and $4 \mathrm{~N}$ respectively, the friction curves of the counter-body (ball) interface and AISI M35 uncoated surface clearly showed the transition of friction regime around 10 meters of sliding. The running-in regime, delimited between the start of the test and the gray dashed line, is characterized by the change of inertia of the system (static to linear movement) and by a marked wear at the contact interface. It happens due to the accommodation of the surfaces in contact, where there is shear of greater roughness that is not sufficient to support the load. The greater presence of wear particles at the interface and the growth of joints contribute to the increase in adhesion, which is reflected in the maximum peaks of friction coefficient, between 0.6 and 0.7 . Soon after, the system's transition stage begins, where the friction coefficient reduces over time. The actual contact area becomes sufficient to support the loading and the wear particles settle in deeper valleys or literally leave the contact interface. After the transition, the steady state regime is reached after 10 meters of sliding. This stabilization can also be the result of a tribofilm of iron oxides $\left(\mathrm{Fe}_{2} \mathrm{O}_{3}, \mathrm{Fe}_{3} \mathrm{O}_{4}\right.$ or $\mathrm{FeO}$ for example) with low resistance to shear that is formed on the surface. The friction coefficient remains stable in a linear trend with arithmetic mean values of approximately 0.32 .

The behavior of the friction coefficient observed in tests 1 and 2 with AISI M35 steel without coating is similar to the behavior presented in tribosystems composed of metallic surfaces in contact and relative movement with no lubrication. The friction curve can be explained as follows ${ }^{20}$ : the running-in regime can be separated into three stages. In the first stage, given the beginning of the relative movement, the removal of the superficial layer occurs, the increase in adhesion due to the increase in the cleaning of the interfacial areas, the increase in the interaction between the roughness and the worn particles, which may gradually increase the value of

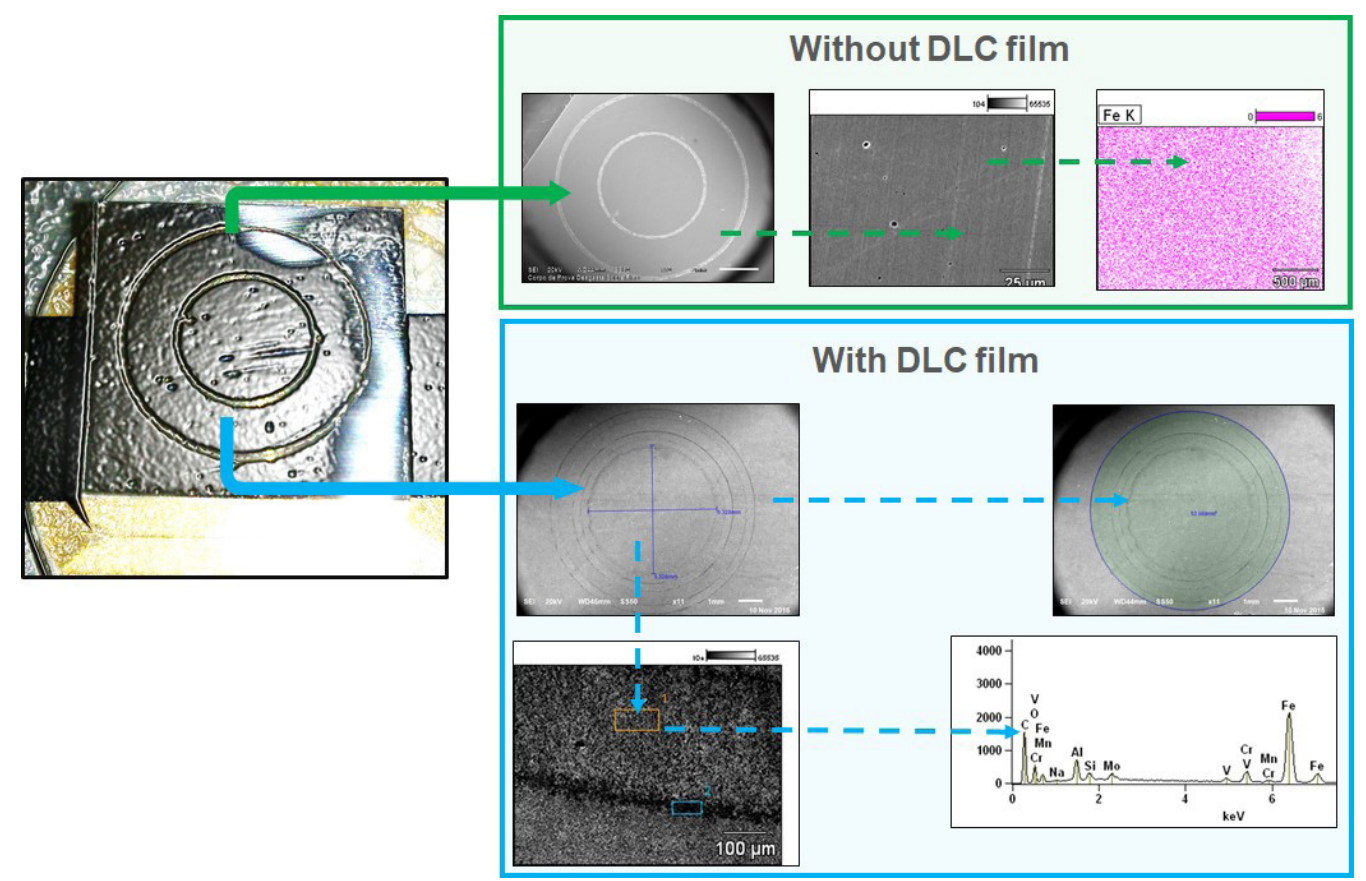

Figure 10. SEM analysis of AISI M35 HSS surfaces with and without DLC coating. 
(a)
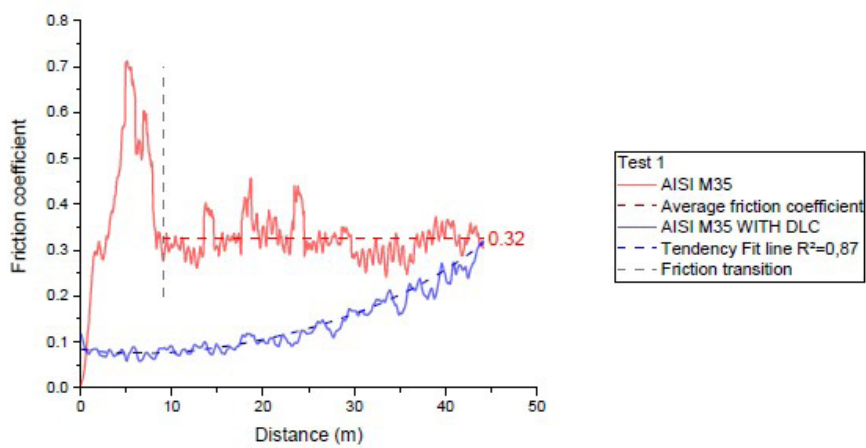

(b)
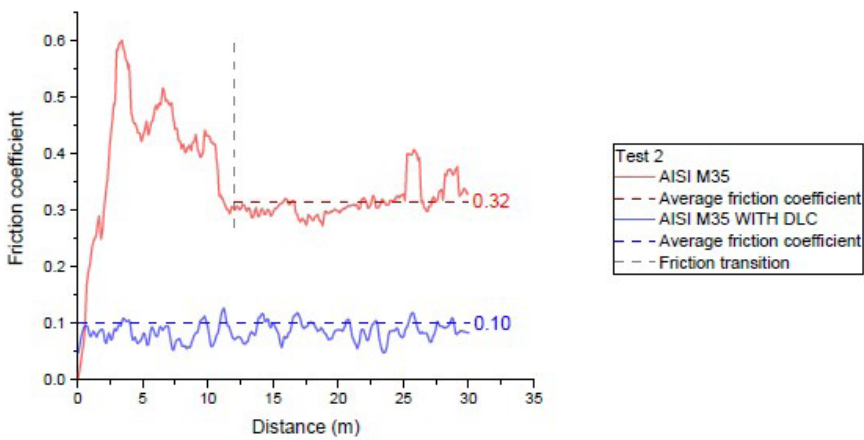

(c)
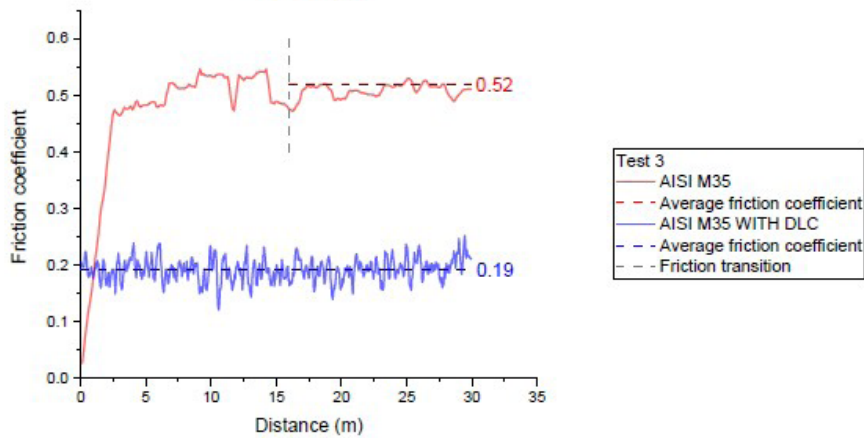

Figure 11. Curves of friction coefficient on ball-on-disc test: test 1 (a), test 2 (b) and test 3 (c).

the friction coefficient. Then, a peak of maximum intensity of the friction coefficient is reached due to the maximum adhesion, with the deformation of the roughness and an increase in the number of residual particles that increase the wear rate. In the third stage, the friction coefficient probably decays because of the formation of a tribofilm or due to a decrease in the groove and roughness deformation processes. After running-in, the steady state is reached, where the surface becomes polished, whose roughness in contact has sufficient mechanical strength to withstand the conditions of loading and relative movement, in addition to the formed tribofilm that lead to practically constant values of the friction coefficient.

In test 3 (Figure 11c) on $6 \mathrm{~N}$ loading there was a change in behavior during the running-in, similar to a climb with small intervals of approximately 2.5 meters of sliding where the friction coefficient remained constant. This may be due to the presence of an oxide film. Small increments of the friction coefficient can represent the breakage of this film, which, however, can be formed again more easily due to the greater linear length of the sliding track that leaves the surface exposed to the environment for longer. After 15 meters of sliding, it is observed that the friction coefficient remains more stable with an arithmetic mean value of 0.52 . The increase in load in tests 1 and 2 did not influence the magnitude of the friction coefficient, while in test 3 there was an increase of $62 \%$ in relation to the average value of 0.32 . In relation to running-in, it was observed that the load provided changes in behavior, as mentioned by ${ }^{11}$. The load is one of the main parameters that modify the running-in. Increasing the normal load implies a more severe roughness deformation, which can be reflected in a "more aggressive cleaning", but faster of the surface, where the friction coefficient presents less dispersion (noise).

In the presence of the DLC, no expressive runningin regimes were observed, as in the uncoated AISI M35. In fact, it is noticed that the tribosytem is modified, since the tested surface is totally different when compared to the uncoated substrate based on the results of the topography (Figure 6) and the chemical constitution (Figure 5). In tests 2 and 3 (Figure 10b and 10c) the DLC provided a reduction of $69 \%$ and $63 \%$ respectively of friction coefficient in 
relation to the uncoated surface ${ }^{8}$. compared to the uncoated SKH51 substrates found similar behavior of DLC in the ball-on-disc trial. In general, this behavior can be attributed to the sum of the hardness and self-lubricating properties of the DLC. It can be related to the diamond-like carbon that increases the roughness resistance to the grooving mechanism ${ }^{66}$ and the carbon similar to graphite that provides the formation of a low shear resistance tribofilm that resembles the condition of solid lubrication ${ }^{63} \cdot{ }^{67}$ confirmed the friction reduction ability of the DLC during the ball-on-disc test by coating the stainless steel 304 (SUS). The authors found a reduction of approximately $67 \%$ in the friction coefficient when comparing to the uncoated SUS ${ }^{23}$.measured friction coefficients between 0.06 and 0.10 in stationary regime in the tribosystem formed by an AISI 52100 pin and a DLCcoated disc of class a-C with less than $20 \% \mathrm{sp}^{3}$ content.

However, it is worth remembering that the friction coefficient is not a property of the material, but particular to each formed tribosystem. The performance of amorphous carbon coatings is therefore also dependent on metallurgical compatibility with the body, temperature and humidity conditions, normal load applied and the peripheral speed used ${ }^{68}$.

In test 1 (Fig. 10a), the DLC showed a different behavior from the other tests. Starting at approximately 0.1, the friction coefficient gradually increased exponentially, as can be seen through the trend curve (dashed blue curve) drawn with $87 \%$ representativeness. Since the friction coefficient in general is proportional to the normal load applied in the tribosystem and the test was performed on the lowest load established in the study methodology, the probable hypothesis for the observed behavior may be related to the parametric combination of maximum rotation $(500 \mathrm{rpm})$ with the runway radius $(3.7 \mathrm{~mm})$. This could have caused a favorable temperature condition to accelerate the wear of the DLC or its failure due to detachment. Although the formation of the graphite layer reduces the system friction, it is also an indication of coating wear, as the contact pressure causes carbon atoms to migrate from the DLC surface to the tribosystem interface. observed behavior similar to test 1 in this study during the ball-on-disc test under dry condition. The authors attributed the increased friction coefficient to the delamination of the coating. The rotation is related to the peripheral speed of the tribosystem relative movement. This peripheral speed can be correlated to the cutting speed mentioned in studies of machining processes, which is the main influencing factor in the cutting temperature. Therefore, the peripheral speed imposed in test 1 probably could have contributed to some microstructural modification of the DLC due to the localized temperature effect of the contact points $^{18}$. evaluated the applicability of the DLC a-C: $\mathrm{H}$ in mixed ceramic cutting tools based on $\mathrm{Al}_{2} \mathrm{O}_{3} / \mathrm{TiCN}$ in dry turning of AISI 52100 steel. The authors stated that the DLC microstructure remains stable up to $260^{\circ} \mathrm{C}$ and above from this temperature its conversion to graphite begins. At the same time, the formation of graphite at the contact interfaces (tool-chip and tool-part) contributes to the machining forces reduction, adhesion and abrasion ${ }^{19}$.also mentioned that the use of non-hydrogenated DLC (up to $2 \%$ hydrogen) requires knowledge of the mechanical properties sensitivity to changes in humidity and temperature in the environment, as the friction coefficient can increase from sudden form above $100^{\circ} \mathrm{C}$.

Despite the $\mathrm{sp}^{3}$ content being mentioned as the main responsible for the DLC resistance, the presence of $\mathrm{sp}^{2}$ hybridizations also contributes to the graphitization property $^{15}$. The contact pressure at the interface leads to the appearance of a thin layer of graphite which is responsible for reducing the friction coefficient. This reduction occurs due to the performance of graphite's solid lubricant, mainly in the presence of moisture where a mixture of vapors, including water, is adsorbed on the surface. These vapors contribute to the reduction of surface energy and to the formation of oxides that end up protecting roughness against wear. Both graphite and the oxides formed have low shear resistance ${ }^{53}$. The formation of this graphite layer was also mentioned by 39 and 40 . The results of nano-hardness and Young's modulus (Fig. 7) can also be attributed to the tribological behavior of the DLC. It is known from the literature that the increase in hardness provides greater wear resistance. Analyzing the contact interface, reducing the difference in hardness between the bodies can benefit the friction coefficient by reducing the growth of joints due to the increased shear resistance of the roughness ${ }^{23}$. mentioned that the friction coefficient reduction will be all the greater as the $\mathrm{sp}^{3}$ content (and therefore the hardness) in hydrogen-free DLC's used in tribosystems with lubrication. The Young's modulus and H/E ratio mentioned by ${ }^{11}$ can also be related to the behavior of the DLC. The higher $\mathrm{H} / \mathrm{E}$ value obtained from the DLC $(0.07 \pm 0.02)$ in relation to the AISI M35 $(0.04 \pm 0.00)$ may mean that the asperities have less resistance to elastic deformation, that is, they can cushion shear contact and normal loading better. Plastic deformation and subsequently the breakdown of asperities can be reduced in this tribosystem.

\section{Conclusion}

This study evaluated the tribological behavior of the DLC deposited on AISI M35 steel, seeking to predict its behavior under machining conditions based on chemical, structural, roughness, mechanical properties of nano-hardness and Young's modulus and performance in wear tests by micro-abrasion and by sliding, comparing conditions with and without the DLC.

Through Raman spectroscopy, it was observed that the PVD deposition process together with its parametric conditions produced an amorphous carbon coating of class a-C consisting mostly of $\mathrm{sp}^{2}$ hybridizations. After deposition, it was noted that the surface was completely modified, where the feed marks of the substrate machining process were completely covered by the DLC, characterized by the presence of several irregularities, a very rugged topography.

In the nano-indentation test, it was observed that hardness and rigidity do not necessarily obey a positive correlation. These results were contradictory in relation to some studies carried out. However, other studies have shown a correlation between density and Young's modulus, where the presence of amorphous content reduces the density of the coating and thus also the rigidity of the coating. Through the $\mathrm{H} / \mathrm{E}$ ratio, it was possible to verify a difference between the DLC and the AISI M35 substrate, probably indicating better coating 
resistance to wear. This was confirmed in the results of the tribological tests.

In the micro-abrasive wear test, on both surfaces, the final wear was predominantly characterized by the removal of material in the direction of sliding of the ball, that is, the presence of scratches/grooves resulting from the combined abrasive action (grooving) of the three-body abrasion and the two-body abrasion. The evidence in which it was possible to affirm that the DLC provided the reduction of wear was the measured diameter of the craters. This result was reflected in a $71 \%$ reduction in the wear coefficient, in relation to the substrate AISI M35.

During the ball-on-disc test, in tests 2 and 3 the DLC provided a reduction of $69 \%$ and $63 \%$, respectively, of the friction coefficient in relation to the uncoated surface. In test 1 , the DLC showed a different behavior from the other tests, the friction coefficient gradually increased exponentially. This observed behavior may be related to excessive wear and/or delamination of the coating. Although $\mathrm{sp}^{3}$ content is mentioned as the main responsible for DLC resistance, the presence of $\mathrm{sp}^{2}$ hybridizations also contributes to the property of graphitization, which was also responsible for reducing the friction coefficient.

From the results presented, in general, it is possible to confirm that the application of DLC coating can provide improvements in the performance of cutting tools made of high-speed steel. However, for real machining conditions, it is observed that it is still necessary to evaluate some factors such as adhesion property, metallurgical compatibility with the substrate and chemical stability under conditions of time, temperature and contact pressure.

\section{Acknowledgments}

The authors would like to acknowledge the Pontifícia Universidade Católica de Minas Gerais; Centro Federal de Educação Tecnológica de Minas Gerais; Nipo-Tec Ferramentas Industriais (Jundiaí, São Paulo, Brazil) for manufacture of all specimens; the Oerlikon Balzers Revestimentos Metálicos (Jundiaí, São Paulo, Brazil) for the DLC coating deposition on the specimens used in this study; Stellantis microscopy laboratory (Betim, Minas Gerais, Brazil) for analyzing the wear by SEM; and CAPES, Coordination for the Improvement of Higher Education Personnel, supported this work [Brasília, Brazil, CEP: 70.040-031, CNPJ: 00889834/0001-08].

\section{References}

1. Conde FF, Diaz JAÁ, Silva GF, Tschiptschin AP. Dependence of wear and mechanical behavior of nitrocarburized/CrN/DLC layer on film thickness. Mater Res. 2019;22(2):e20180499.

2. Zhou Y, Guo P, Sun L, Liu L, Xu X, Li W, et al. Microstructure and property evolution of diamond-like carbon films co-doped by Al and Ti with different ratios. Surf Coat Tech. 2019;361:83.

3. Ferrari AC, Robertson J. Interpretation of Raman spectra of disordered and amorphous carbon. Phys Rev B Condens Matter Mater Phys. 2000;61(20):14095-107.

4. Salah N, Alshahrie A, Iqbal J, Hasan PMZ, Abdel-wahab MS. Tribological behavior of diamond-like carbon thin films deposited by the pulse laser technique at different substrate temperatures. Tribol Int. 2016;103:274.
5. Popescu C, Cristea D, Bita B, Cristescu R, Craciun D, Chioibasu $\mathrm{G}$, et al. An experimental study on nano-carbon films as an antiwear protection for drilling tools. Coatings. 2017;7(12):228.

6. Martins PS, Gonçalves Carneiro JR, Ba ECT, Vieira VF. Study on roughness and form errors linked with tool wear in the drilling process of an Al-Si alloy under high cutting speed using coated diamond-like carbon high-speed steel drill bits. J Manuf Process. 2021:62.

7. Constantinou M, Pervolaraki M, Koutsokeras L, Prouskas C, Patsalas P, Kelires P, et al. Enhancing the nanoscratch resistance of pulsed laser deposited DLC films through molybdenumdoping. Surf Coat Tech. 2017;330:185.

8. Kao WH, Su YL, Horng JH, Yu CC. Effects of pulse power and argon flux flow rate on mechanical and tribological properties of diamond-like carbon coatings prepared using high power impulse magnetron sputtering technology. Thin Solid Films. 2020;693:137712.

9. Dash L, Padhan S, Das SR. Experimental investigations on surface integrity and chip morphology in hard tuning of AISI D3 steel under sustainable nanofluid-based minimum quantity lubrication. J Braz Soc Mech Sci Eng. 2020;42(10):500.

10. Padhan S, Das A, Santoshwar A, Dharmendrabhai TR, Das SR Sustainability Assessment and machinability investigation of austenitic stainless steel in finish turning with advanced ultrahard SiAlON ceramic tool under different cutting environments. Silicon. 2021;13(1):119.

11. Souza PS, Santos AJ, Cotrim MAP, Abrão AM, Câmara MA. Analysis of the surface energy interactions in the tribological behavior of ALCrN and TIAIN coatings. Tribol Int. 2020;146:106206.

12. Silva WM, Jesus LM, Carneiro JR, Souza PS, Martins PS, Trava-Airoldi VJ. Performance of carbide tools coated with DLC in the drilling of SAE 323 aluminum alloy. Surf Coat Tech. 2015;284:404.

13. Melo Silva W, Martins PS, Carvalho VE, da Cruz NC, Claudino E, Carneiro JRG. Improving precision in aluminum alloy machining due to the application of diamond-like carbon thin film. J Tribol. 2021;143(7):071403.

14. Behera RK, Samal BP, Panigrahi SC, Das SR. Optimization of erosion wears of $\mathrm{Al}-\mathrm{Mg}-\mathrm{Si}-\mathrm{Cu}-\mathrm{SiC}$ composite produced by the PM method. Corros Rev. 2021;39(1):63-75.

15. Li X, Sawaki T, Kousaka H, Murashima M, Umehara N. Effect of mating materials on wear properties of amorphous hydrogenated carbon (a-C:H) coating and tetrahedral amorphous carbon (taC) coating in base oil boundary lubrication condition. J Tribol. 2017;15:1-20.

16. Nowakowska-Langier K, Chodun R, Minikayev R, Okrasa S, Strzelecki GW, Wicher B, et al. Copper nitride layers synthesized by pulsed magnetron sputtering. Thin Solid Films. 2018;645:32.

17. Hanby BVT, Stuart BW, Grant C, Moffat J, Blissett J, Gerada $\mathrm{C}$, et al. Dielectric breakdown of alumina thin films produced by pulsed direct current magnetron sputtering. Thin Solid Films. 2018;662:145.

18. Sateesh Kumar C, Majumder H, Khan A, Patel SK. Applicability of DLC and WC/C low friction coatings on $\mathrm{Al}_{2} \mathrm{O}_{3} / \mathrm{TiCN}$ mixed ceramic cutting tools for dry machining of hardened 52100 steel. Ceram Int. 2020;46(8):11889-97.

19. Bhowmick S, Banerji A, Alpas AT. Tribological behavior of Al-6.5\%,-12\%,-18.5\% Si alloys during machining using CVD diamond and DLC coated tools. Surf Coat Tech. 2015;284:353.

20. Ba ECT, Dumont MR, Martins PS, Drumond RM, Martins da Cruz MP, Vieira VF. Investigation of the effects of skewness Rsk and kurtosis Rku on tribological behavior in a pin-on-disc test of surfaces machined by conventional milling and turning processes. Mater Res. 2021;24(2):e20200435.

21. Silva WM, Souza PS, Carneiro JR. Methods of data analysis for the ball cratering test on TiN and DLC coated steel. Mater Res. 2016;19(1):9-17. 
22. Ardila MAN, Costa HL, Mello JDB. Influence of the ball material on friction and wear in microabrasion tests. Wear. 2020;450-451:203266.

23. Mabuchi Y, Higuchi T, Weihnacht V. Effect of sp $2 / \mathrm{sp} 3$ bonding ratio and nitrogen content on friction properties of hydrogenfree DLC coatings. Tribol Int. 2013;62:130.

24. Soffritti C, Fortini A, Sola R, Fabbri E, Merlin M, Garagnani GL. Influence of vacuum heat treatments on microstructure and mechanical properties of M35 high speed steel. Metals. 2020;10(5):643.

25. Gsellmann M, Klünsner T, Mitterer C, Marsoner S, Skordaris G, Bouzakis K, et al. Near-interface cracking in a TiN coated high speed steel due to combined shear and compression under cyclic impact loading. Surf Coat Tech. 2020:394.

26. Egels G, Wulbieter N, Weber S, Theisen W. A computational approach to the microstructural design of high-speed steels. Steel Res Int. 2020;91(5):1900455.

27. Tshabalala L, Sono O, Makoana W, Masindi J, Maluleke $\mathrm{O}$, Johnston C, et al. Axial fatigue behaviour of additively manufactured tool steels. Mater Today Proc. 2021;38.

28. Pant G, Singh AP, Sharma HK. Cooling rate characteristics of vanadium based micro alloyed steel. Mater Today Proc. 2020;26.

29. Maizza G, Pero R, de Marco F, Ohmura T. Correlation between the indentation properties and microstructure of dissimilar capacitor discharge welded WC-Co/high-speed steel joints. Materials. 2020;13(11):2657.

30. Sivaprahasam D, Chandrasekhar SB, Murugan K, Prabhakar KVP. Microstructure and mechanical properties of M62 highspeed steel powder consolidated by high-temperature gas extrusion. Mater Res Innov. 2020;24(1):52-7.

31. Masoumi M, Echeverri EAA, Tschiptschin AP, Goldenstein H. Improvement of wear resistance in a pearlitic rail steel via quenching and partitioning processing. Sci Rep. 2019;9(1):7454.

32. Țălu Ş, Solaymani S, Rezaee S, Nezafat NB. The evaluation of surface topography changes in nanoscaled 2,6-diphenyl anthracene thin films by atomic force microscopy. Microsc Res Tech. 2021;84(1):89-100.

33. Miller JD, Veeramasuneni S, Drelich J, Yalamanchili MR, Yamauchi G. Effect of roughness as determined by atomic force microscopy on the wetting properties of PTFE thin films. Polym Eng Sci. 1996;36(14):1849-55.

34. Oliver WC, Pharr GM. An improved technique for determining hardness and elastic modulus using load and displacement sensing indentation experiments. J Mater Res. 1992;7(6):1564-83.

35. Almeida EAS, Krelling AP, Milan JCG, Costa CE. Microabrasive wear mechanisms of P/M AISI M2 steel with different surface treatments. Surf Coat Tech. 2018;333:238-46.

36. Teles VC, de Mello JDB, da Silva WM Jr. Abrasive wear of multilayered/gradient CrAlSiN PVD coatings: effect of interface roughness and of superficial flaws. Wear. 2017;376-377:1691.

37. Muthuraja A, Naik S, Rajak DK, Pruncu CI. Experimental investigation on chromium-diamond like carbon (Cr-DLC) coating through plasma enhanced chemical vapour deposition (PECVD) on the nozzle needle surface. Diamond Related Materials. 2019;100:107588.

38. Gobbi SJ, Gobbi VJ, Reinke G, Muterlle PV, Rosa DM. Ultralow-temperature process effects on microscale abrasion of tool steel AISI D2. Mater Sci Technol. 2019;35(11):1355-64.

39. Manninen NK, Ribeiro F, Escudeiro A, Polcar T, Carvalho $\mathrm{S}$, Cavaleiro A. Influence of Ag content on mechanical and tribological behavior of DLC coatings. Surf Coat Tech. 2013;232:440

40. Kovacı H, Baran Ö, Yetim AF, Bozkurt YB, Kara L, Çelik A. The friction and wear performance of DLC coatings deposited on plasma nitrided AISI 4140 steel by magnetron sputtering under air and vacuum conditions. Surf Coat Tech. 2018;349:969.
41. Bhargava AK, Banerjee MK. Hardenability of steel. In: Hashmi MSJ, editor. Comprehensive materials finishing. Oxford: Elsevier; 2017.

42. Podgornik B, Sedlaček M, Žužek B, Guštin A. Properties of tool steels and their importance when used in a coated system. Coatings. 2020;10(3):265.

43. Ren Y, Erdmann I, Küzün B, Deuerler F, Buck V. Effect of deposition parameters on wear particle size distribution of DLC coatings. Diamond Related Materials. 2012;23:184.

44. Nakamura M, Takagawa Y, Miura K, Kobata J, Zhu W, Nishiike $\mathrm{N}$, et al. Structural alteration induced by substrate bias voltage variation in diamond-like carbon films fabricated by unbalanced magnetron sputtering. Diamond Related Materials. 2018;90:214.

45. Donnet C. Recent progress on the tribology of doped diamondlike and carbon alloy coatings: a review. Surf Coat Tech. 1998;100-101:180.

46. Zhu W, Arao K, Nakamura M, Takagawa Y, Miura K, Kobata $\mathrm{J}$, et al. Raman spectroscopic studies of stress-induced structure alteration in diamond-like carbon films. Diamond Related Materials. 2019;94:1.

47. Ferrari AC. Non-destructive characterisation of carbon films. In: Donnet C, Erdemir A, editors. Tribology of diamond-like carbon films. Boston: Springer US; 2008.

48. Casiraghi C, Robertson J, Ferrari AC. Diamond-like carbon for data and beer storage. Mater Today. 2007;10(1-2):44-53.

49. Gutiérrez BJM, Conceição K, de Andrade VM, Trava-Airoldi VJ, Capote G. High antibacterial properties of DLC film doped with nanodiamond. Surf Coat Tech. 2019;375:395.

50. Zhang TF, Deng QY, Liu B, Wu BJ, Jing FJ, Leng YX, et al. Wear and corrosion properties of diamond like carbon (DLC) coating on stainless steel, CoCrMo and Ti6Al4V substrates. Surf Coat Tech. 2015;273:12

51. Qi M, Xiao J, Cheng Y, Wang Z, Jiang A, Guo Y, et al. Effect of various nitrogen flow ratios on the optical properties of (Hf:N)-DLC films prepared by reactive magnetron sputtering. AIP Adv. 2017;7(8):085012.

52. Liu JQ, Li LJ, Wei B, Wen F, Cao HT, Pei YT. Effect of sputtering pressure on the surface topography, structure, wettability and tribological performance of DLC films coated on rubber by magnetron sputtering. Surf Coat Tech. 2019;365:33.

53. Wang Y, Wang Y, Li X, Li A, Lu Z, Zhang G, et al. The friction and wear properties of metal-doped DLC films under currentcarrying condition. Tribol Trans. 2019;62(6):1119-28.

54. Li L, Zhang H, Zhang Y, Chu PK, Tian X, Xia L, et al. Structural analysis of arc deposited diamond-like carbon films by Raman and X-ray photoelectron spectroscopy. Mater Sci Eng B. 2002;94(1):95-101.

55. LiBassi A, Ferrari AC, Stolojan V, Tanner BK, Robertson J, Brown LM. Density, $\mathrm{sp}^{3}$ content and internal layering of DLC films by X-ray reflectivity and electron energy loss spectroscopy. Diamond Related Materials. 2000;9(3-6):771-6.

56. Charitidis CA. Nanomechanical and nanotribological properties of carbon-based thin films: a review. Int J Refract Met Hard Mater. 2010;28(1):51-70.

57. Popov IV, Görne AL, Tchougréeff AL, Dronskowski R. Relative stability of diamond and graphite as seen through bonds and hybridizations. Phys Chem Chem Phys. 2019;21(21):10961-9.

58. Graphite KJ. Properties, uses and South Australian resources. Mesa J. 2017;84(3):28-41.

59. Haddock D, Parker T, Spindloe C, Tolley M. Characterisation of Diamond-Like Carbon (DLC) laser targets by Raman spectroscopy. J Phys Conf Ser. 2016;713:012007.

60. Lee KB, Kwon H, Kwon H, Yang HR. Effects of alloying additions and austenitizing treatments on secondary hardening and fracture behavior for martensitic steels containing both Mo and W. Metall Mater Trans, A Phys Metall Mater Sci. 2001;32(7):1659-70. 
61. Sahay S, Pandey MK, Kar AK. Metal concentration dependent mechanical properties of electrodeposited nickel incorporated diamond like carbon (Ni-DLC) thin films studied by nanoindentation. Appl Surf Sci. 2019;489:73.

62. Rebholz C, Leyland A, Matthews A, Charitidis C, Logothetidis S, Schneider D. Correlation of elastic modulus, hardness and density for sputtered TiAlBN thin films. Thin Solid Films. 2006;514(1-2):81-6.

63. Grenadyorov AS, Oskirko VO, Solovyev AA, Oskomov KV, Khlusov IA. Wear and corrosion resistance of a-C:H:SiOx coating on medical 316L Stainless steel. J Mater Eng Perform. 2021;30(2):1099-109.

64. Mercado-Solis RD, Mata-Maldonado JG, Quinones-Salinas MA, Rodriguez-de-Anda E, Servín-Castañeda R. Micro-scale abrasive wear testing of CrN duplex PVD Coating on pre-nitrided tool steel. Mater Res. 2017;20(4):1092-102.
65. Steier VF, Pires MST, Doca T. The influence of diamond-like carbon and anodised aluminium oxide coatings on the surface properties of the SAE 305 aluminium alloy. J Braz Soc Mech Sci Eng. 2018;40(2):41

66. de Oliveira Correia RFB, Wachesk CC, Hurtado CR, Damm DD, Taiariol TS, Tada DB, et al. CVD-diamond nanoparticle synthesis for DLC film application. J Nanopart Res. 2020;22(9):293.

67. Sakurai K, Hiratsuka M, Nakamori H, Namiki K, Hirakuri K Evaluation of sliding properties and durability of DLC coating for medical devices. Diamond Related Materials. 2019;96:97.

68. Dorner-Reisel A, Engel A, Svoboda S, Schürer C, Weißmantel S. Laser structuring of hydrogenated DLC scaffolds: raman spectroscopy and nanotribology. Diamond Related Materials. 2020;108(Oct):107787. 